\title{
WestVirginiaUniversity
}

THE RESEARCH REPOSITORY @ WVU

Graduate Theses, Dissertations, and Problem Reports

2017

\section{Occupational Exposure to Blood and Bodily Fluids among Health Care Workers}

Riyadh Alhazmi

Follow this and additional works at: https://researchrepository.wvu.edu/etd

\section{Recommended Citation}

Alhazmi, Riyadh, "Occupational Exposure to Blood and Bodily Fluids among Health Care Workers" (2017). Graduate Theses, Dissertations, and Problem Reports. 5065.

https://researchrepository.wvu.edu/etd/5065

This Dissertation is protected by copyright and/or related rights. It has been brought to you by the The Research Repository @ WVU with permission from the rights-holder(s). You are free to use this Dissertation in any way that is permitted by the copyright and related rights legislation that applies to your use. For other uses you must obtain permission from the rights-holder(s) directly, unless additional rights are indicated by a Creative Commons license in the record and/ or on the work itself. This Dissertation has been accepted for inclusion in WVU Graduate Theses, Dissertations, and Problem Reports collection by an authorized administrator of The Research Repository @ WVU.

For more information, please contact researchrepository@mail.wvu.edu. 


\title{
Occupational Exposure to Blood and Bodily Fluids Among Health Care Workers
}

\author{
Riyadh Alhazmi \\ A dissertation submitted to \\ The College of Public Health at West Virginia University \\ In partial satisfaction of the requirements for the degree of \\ Doctor of Philosophy in \\ Public Health/Occupational and Environmental Health Sciences
}

\author{
Committee Members: \\ Michael McCawley, Ph.D., Chair \\ Wen Sijin, Ph.D. \\ Anna Allen, Ph.D. \\ Gregory Schaefer, DO \\ Department of Occupational and Environmental Health Sciences \\ Morgantown, West Virginia
}

Fall 2017

Keywords:

Emergency medical services; healthcare providers, exposure, injuries; prehospital; needlestick; paramedic; EMS Copyright 2017 Riyadh Alhazmi 


\section{Occupational Exposure to Blood and Bodily Fluids Among Health Care Workers}

\section{Riyadh Alhazmi}

Health Care workers (HCWs) face a variety of occupational exposure in workplace. One of the most significant concerns among for HCWs including Emergency Medical Services (EMS) providers is to expose to blood and bodily fluids during the performance of their duties, resulting in concerns regarding transmission of blood-borne pathogens such as hepatitis B virus (HBV), hepatitis $\mathrm{C}$ virus (HCV), and human immunodeficiency virus (HIV). To manage the unpleasant effects of the harmful exposure to infected blood and bodily fluids, HCWs including EMS providers to follow complete compliance of standard precautions (SPs) recommendations and to attend continuing education regarding blood borne pathogens prevention. In this study, the extent of knowledge, consistency, and practices of SPs were assessed and characteristics of rural and urban EMS providers that predicted lacking compliance with SPs were explored. In addition, knowledge of EMS providers regarding Needle stick injuries was assessed. Finally, blood and bodily fluids exposure incidents among hospital-based HCWs was examined. 


\section{TABLE OF CONTENTS}

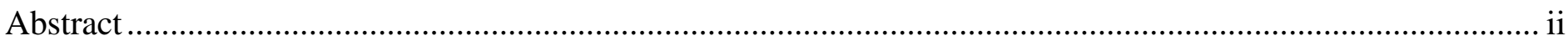

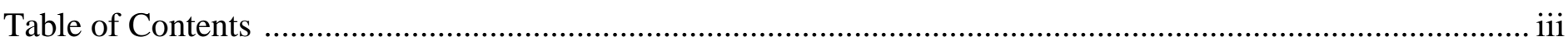

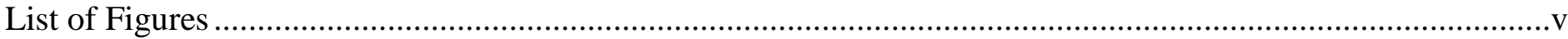

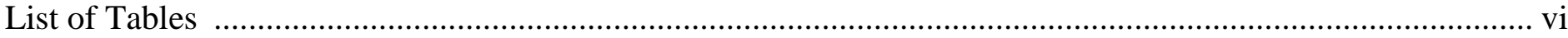

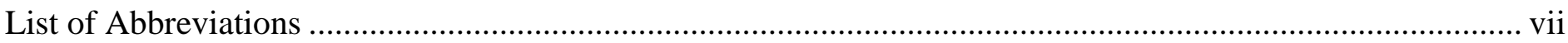

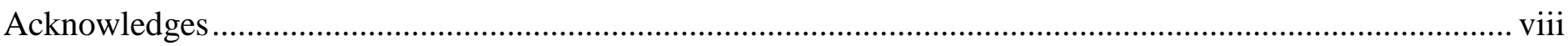

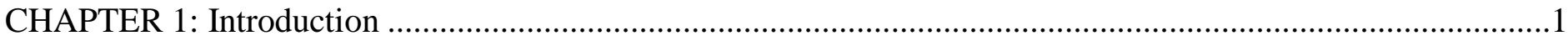

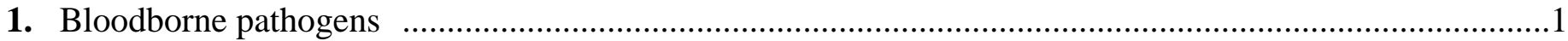

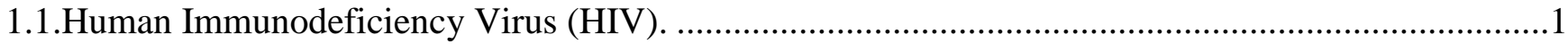

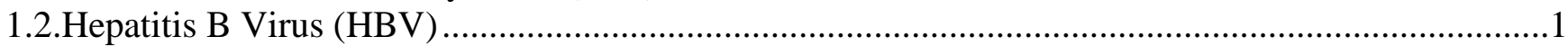

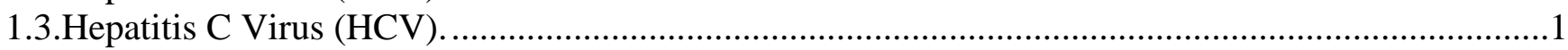

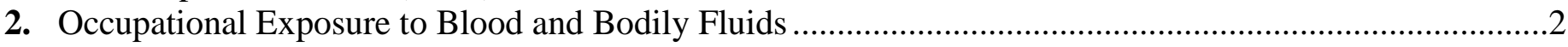

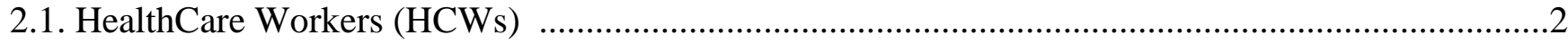

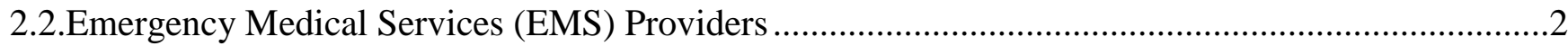

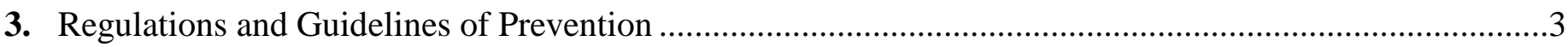

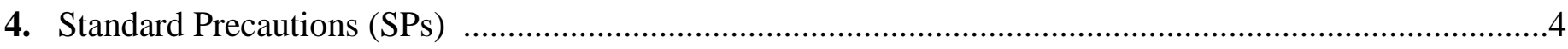

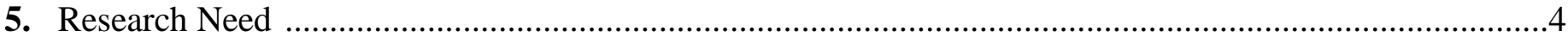

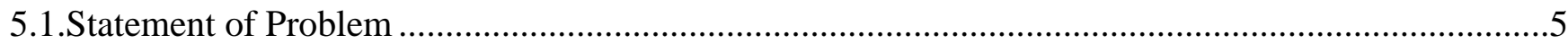

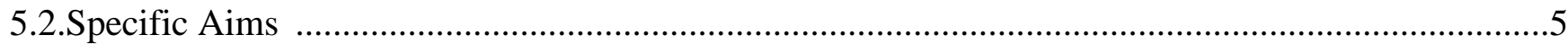

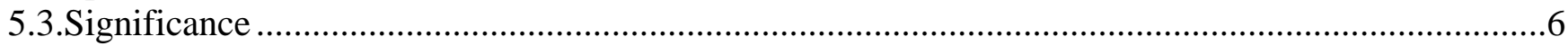

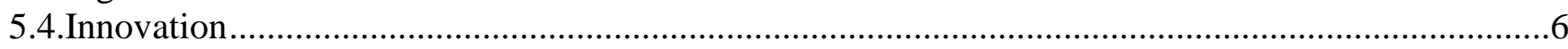

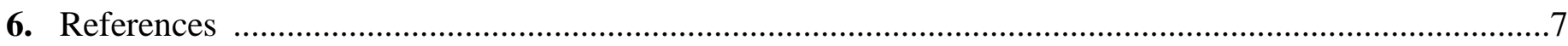

CHAPTER 2: Standard Precautions among Emergency Medical Services in Urban and Rural Areas .................9

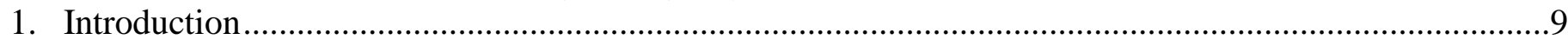

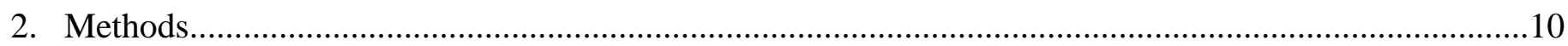

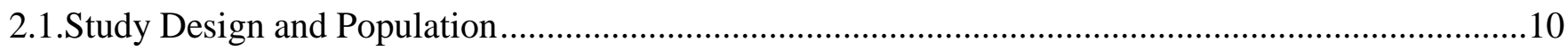

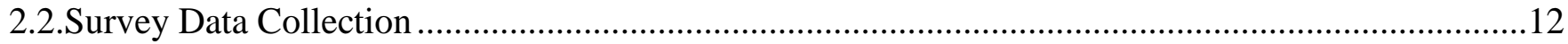

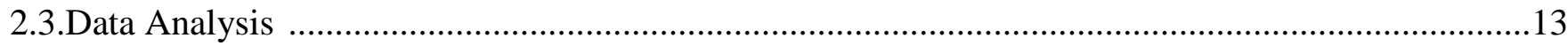

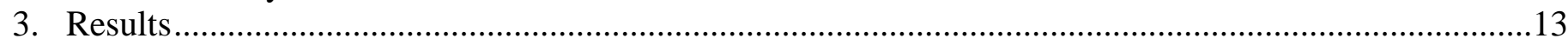

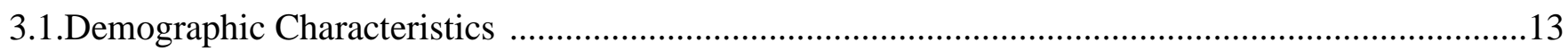

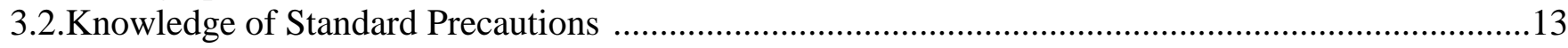

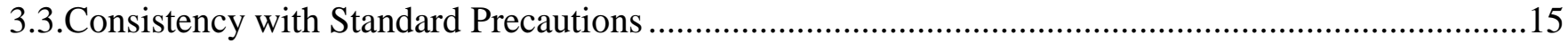

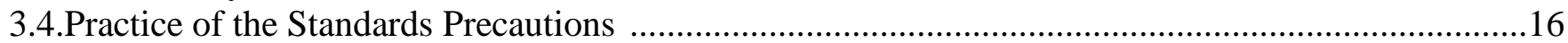

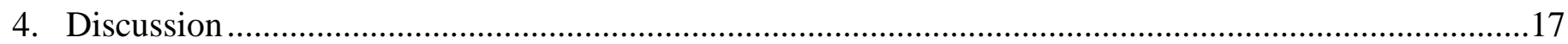

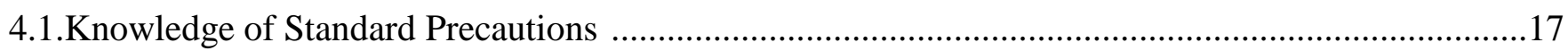

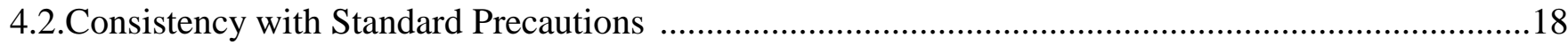

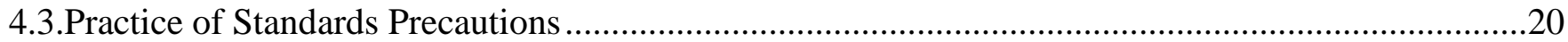

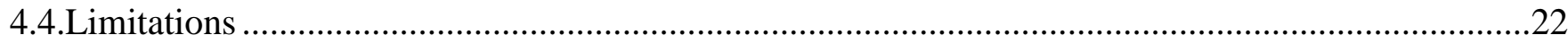

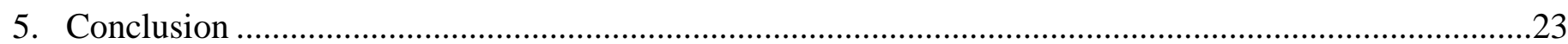

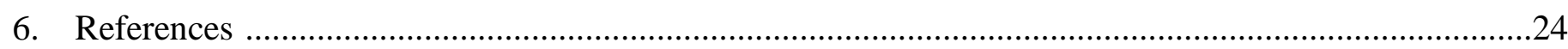

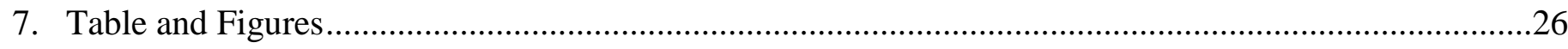

CHAPTER 3: Needlestick Injuries among Emergency Medical Services Providers in Urban and Rural Areas ..41

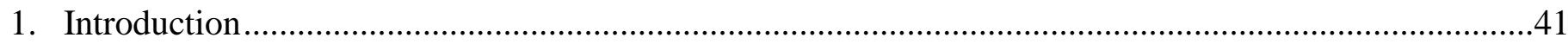

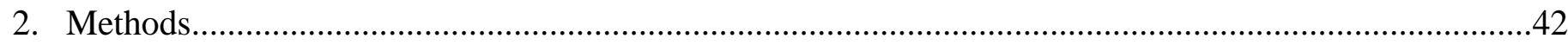




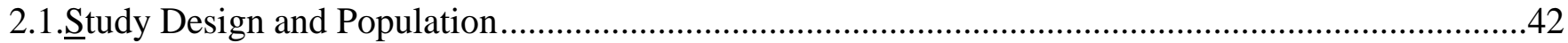

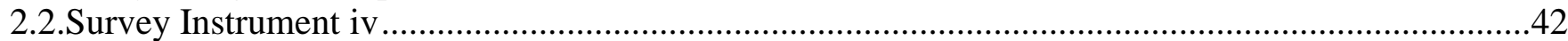

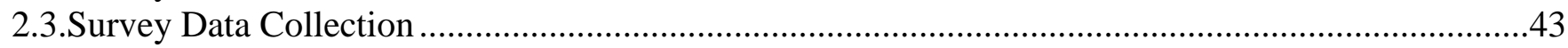

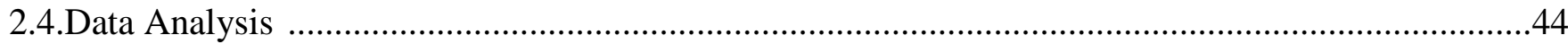

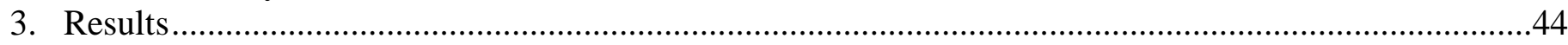

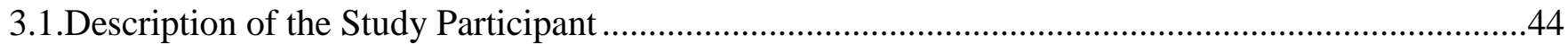

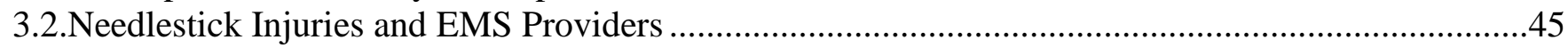

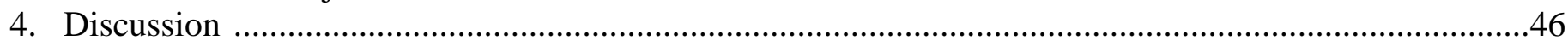

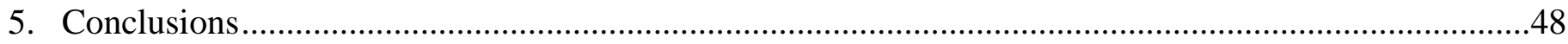

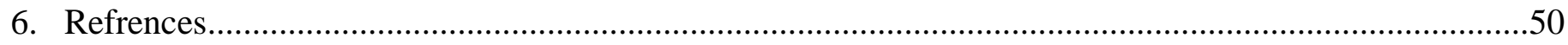

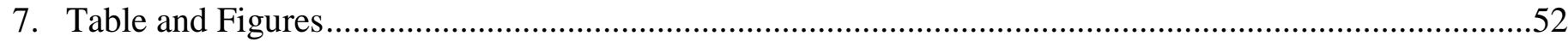

CHAPTER 4: Occupational Exposure to Blood and body fluids among Health Care Workers .........................57

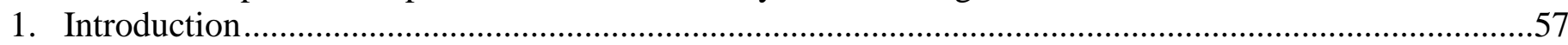

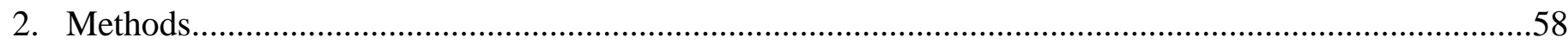

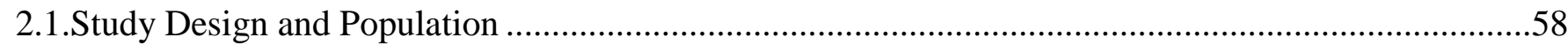

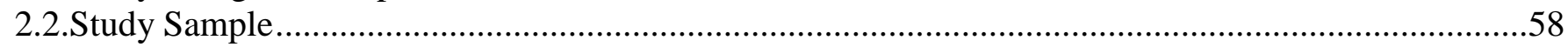

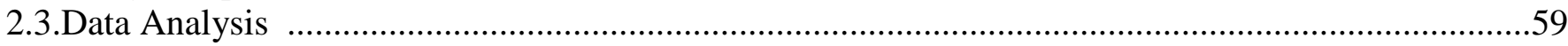

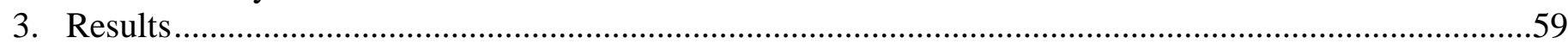

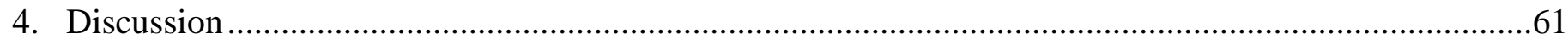

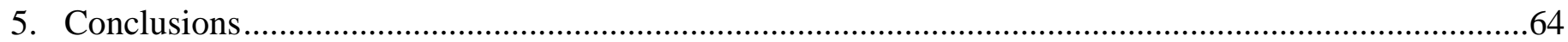

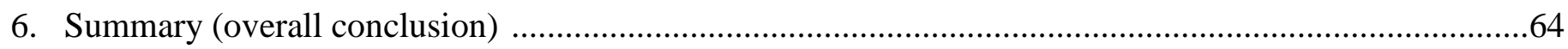

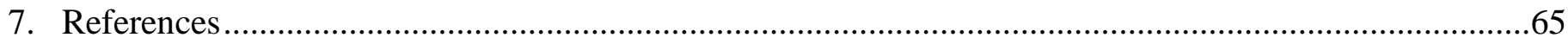

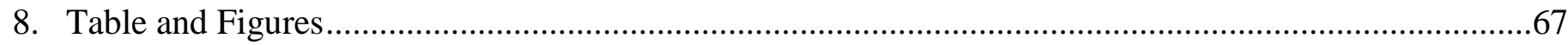




\section{LIST OF FIGURES}

Figure 2.7.1: Stratification of Gender and Residence to with Knowledge of SPs......................30

Figure 2.7.2: Attitude toward the Use of SPs on Every Patient among .................................... 31

Figure 2.7.3: Stratification Gender and Residence with Attitude Toward SPs ..........................34

Figure 2.7.4: Stratification of Gender and Residence to with Practice of SPs $(n=248)$..............39

Figure 3.7.1: Stratification of Gender and Residence to with Needlestick injuries....................56 


\section{LIST OF TABLES}

Table 2.7.1: Demographics of EMS Providers $(n=248)$.........................................................26

Table 2.7.2: Knowledge of the Purpose of Standard Precautions..................................................22

Table 2.7.3: Relationship between Inadequate Knowledge of SPs and Demographics ..................28

Table 2.7.4: Logistic Regression Modeling of Knowledge of Standard Precautions .......................29

Table 2. 7.5: Relationship between Attitudes toward the Use of SPs and Demographics ..............32

Table 2.7.6: Logistic Regression Modeling of Attitudes toward Standard Precautions ....................33

Table 2.7.7: Reasons to Not Use Standard Precautions on Every Patient among EMS Providers....35

Table 2.7. 8: Practice of Standard Precautions ...............................................................................36

Table 2.7. 9: Relationship between Practice of SPs and Demographics of the EMS Providers........37

Table 2.7.10: Logistic Regression Modeling of Attitude of Standard Precautions ..........................38

Table 2.7.11: Barriers to the Use of Standard Precautions .....................................................40

Table 3. 7.1: Demographics of EMS Providers $(n=247)$........................................................52

Table 3.7.2: Demographics of EMS Providers Reporting a NSIs in Last 12 months......................54

Table 3.7.3: Adjusted Logistic Regression Modeling of NSIs $(n=247)$........................................55

Table 4. 7.1: Demographics and Relationships of HCWs Reporting Occupational Exposure..........67

Table 4.7.2: Demographics and Relationships of HCWs Reporting Routes of Percutaneous .........68

Table 4.7.3: Healthcare Workers Reporting Occupational Exposure to Infectious Diseases ...........69 


\section{LIST OF ABBREVIATIONS}

BBF $=$ Blood and Body Fluids

Bloodborne Pathogens Standard (BPS)

$\mathrm{CDC}=$ the Centers for Disease Control and Prevention

EMT $=$ Emergency Medical Technician

EMS $=$ Emergency Medical Services

NSIs $=$ needlestick injuries

HCWs $=$ Health Care workers

$\mathrm{HBV}=$ hepatitis $\mathrm{B}$ virus

$\mathrm{HCV}=$ hepatitis $\mathrm{C}$ virus

HIV =Human immunodeficiency virus

NSIs $=$ Needlestick Injuries

OSHA $=$ the United States Occupational Safety and Health Administration

PIs $=$ Percutaneous Injuries (PIs).

$\mathrm{SESIP}=$ sharp with engineered sharps injury protection

SPs $=$ standard precautions 


\section{ACKNOWLEDGEMENTS}

I would like to thank my dissertation committee for their support in completing this dissertation. I want to thank Dr. Michael McCawley, for serving as a chair of my dissertation committee and for the encouragement he provided through the writing process of this study. I want also to express appreciation to Dr. Wen Sijin, Dr. Anna Allen, and Dr. Gregory Schaefer, for serving on my dissertation committee and providing guidance based upon their expertise. I am sincerely thankful to my parents for their support during my years in PhD program. I want to thank my wife, Asma, for her support and encouragement. I would also like to thank my children -

Danah, Naif and Yara - for their understanding my circumstances and willingness to adapt to my absence throughout the program. I would also to express my appreciation to certain supporters who made this dissertation possible. First, my deepest thanks to my friends Yahya Alamir and Khalid Alhussain for thier support throughout my studies. I would also extend my appreciation to the EMS agencies who helped me in distributing the survey link to their memberships and to health employee clinic in Ruby hospital for providing the dataset. 


\section{CHAPTER 1: INTRODUCTION}

\section{Bloodborne Pathogens}

Bloodborne pathogens are microorganisms that contain an infectious disease. The infectious disease can be transmitted through exposure to infected blood and body fluids via needlestick and other sharps injuries, mucous membrane, and skin exposures [1]. Three of the most common bloodborne pathogens of which healthcare workers (HCWs) are at risk of transmission are the human immunodeficiency virus (HIV), hepatitis B virus (HBV), and hepatitis $\mathrm{C}$ virus (HCV) [2].

\subsection{Human Immunodeficiency Virus (HIV)}

In 2015, 39,513 individuals were diagnosed with HIV, and young gay and bisexual men accounted for $84 \%$ of all new HIV diagnoses in people aged 13-24 [3]. An estimated 1.1 million individuals were living with HIV at the end of 2014, with the age range of 13-24 especially affected by HIV [3]. The annual number of new diagnoses dropped by $9 \%$ from 2010 to 2014 [3]. A total of 6,721 people died from HIV in 2014, and HIV remains a significant cause of death in the United States [3].

\subsection{Hepatitis B Virus (HBV)}

HBV is a major public health issue in worldwide; there were an estimated 3,370 cases of acute HBV in 2015 in the United States (1.1 per 100,000), which was higher than in $2014(0.9$ per 100,000) [3]. In 2015, there were 14,416 confirmed reports of chronic HBV [4]. The rates of death by HBV dropped from 1,804 cases in 2011 to $\mathbf{1 , 7 1 5}$ cases in 2015 [4]. In 2015 alone, those ages 55-64 had the highest rates of HBV-related deaths (1.49 per 100,000), and the lowest rates were among those between the ages of 0-34 $(0.02$ per 100,000) [4]. In addition, the rate of males was 0.72 per 100,000 , which was higher than the rate of females $(0.22$ per 100,000$)$ 
[4]. An effective vaccination has been widely distributed and available in the United States since 2001; therefore, HBV is no longer a major concern for occupational exposure [5].

\subsection{Hepatitis C Virus (HCV)}

There were 2,436 cases of acute HCV (0.8 per 100,000) in 2015 alone, while there are an estimated $\mathbf{1 8 1 , 8 7 1}$ cases who are living with HCV in 2015 [4]. The rates of death with HCV increased from $\mathbf{1 7 , 7 2 1}$ cases in 2011 to $\mathbf{1 9 , 6 2 9}$ cases in 2015 [4]. In 2015 alone, those ages 55-64 had the highest rates of HCV-related deaths $(23.73$ per 100,000), and the lowest rates were among those between the ages of $0-34(0.13$ per 100,000$)$ [4]. In addition, the rate of males was 7.31 per 100,000 , which is higher than the rate than of females $(2.71$ per 100,000) [4].

\section{Occupational Exposure to Blood and Bodily Fluids}

\subsection{Healthcare Workers (HCWs)}

_An estimated 320, 471 employees die annually from infectious diseases at their workplace [6]. HCWs, public safety workers, and other types of workers can be exposed to bodily fluids through mucous membranes, non-intact skin contact, and percutaneous injuries (PIs). HCWs are defined as any person whose role is directly associated with healthcare, including physicians, paramedics, nurses, dentists, medical technicians, medical assistants, and students in the healthcare field [7].

Compared to many other types of occupations, $\mathrm{HCW}$ s are at a greater risk of harm from exposure to blood, bodily fluids, and other pathogens. A study revealed a high level of occupational exposure to blood among HCWs [8]. Specifically, data analyzed from the National Occupational Mortality Surveillance (NOMS) system showed that HCWs are at increased risk of HCV due to work-related exposures to HCV-infected bodily fluids [8]. In the United Kingdom, a study revealed that $100 \%$ of occupationally-transmitted HCV to HCWs involved a PI [9]. The CDC estimated that 385,000 PIs are incurred by hospital-based HCWs each year in the 
United States [10].These data show that, even among HCWs who have higher exposure, some occupations of HCWs may be more susceptible to increased rates of exposure to bodily fluids than others.

\subsection{Emergency Medical Services (EMS) Providers}

Emergency Medical Services (EMS) providers deliver pre-hospital care to patients and therefore have significant potential for pathogen transmission, especially in the case of severe injuries and illness. EMS providers are often exposed to potentially harmful bodily fluids. PIs among EMS providers are of concern due to the risk of transmission of blood borne pathogens [10]. Non-intact skin exposure to bodily fluids has a higher rate than any other route of exposure to bodily fluids among EMS providers [12]. However, the PI rate of EMS providers is higher than most hospital-based HCWs in United States [13].

\section{Regulations and Prevention Guidelines}

There are several levels of regulations and standards to support the occupational health and safety of HCWs. At the federal level, the Centers for Disease Control and Prevention (CDC) and the United States Occupational and Safety and Health Administration (OSHA) have promoted principles to decrease the risk of exposure by HCWs to blood borne pathogens. The first attempt started in response to the emergence of HIV in

the 1980s; the CDC established guidelines for standard precautions (SPs) to prevent contact between HCWs and the blood or bodily fluids of patients [14]. These guidelines served as the foundation for the OSHA's Bloodborne Pathogens Standard (BPS) in 1991. The BPS included a ban on recapping contaminated/ used needles and established the need for sharps disposal containers at the point-of-use, which was in addition to guidelines established by the CDC during 1980s [15, 16]. The BPS listed "engineering controls" as the chosen method to reduce the risk of needle stick injuries to HCWs [15].

In 2000, The United States Congress passed the Needlestick Safety and Prevention Act to promote and explain the language, used by OSHA in the BPS, involving needlesticks and the sharps safety program [15]. 
OSHA made corresponding changes to the BPS; the revised BPS went into effect in April 2001. The major change of the revised BPS was outlining a definition of a "sharp with engineered sharps injury protection" (SESIP) [17]. These efforts by OSHA and the CDC resulted in well-developed and defined regulations regarding prevention of blood borne pathogen exposure and needlestick injury for HCWs.

\section{Standard Precautions (SPs)}

SPs were created to prevent the exposure of blood borne pathogens through PIs or non-percutaneous exposure to HCWs. Non-compliance with SPs increases the risk of occupational exposure, thereby increasing the risk of acquiring infectious diseases. The extensive failure to comply with SPs significantly increases the rates of exposure, thus endangering $\mathrm{HCW}$ s and patients $[18,19,20]$. Additionally, some occupations of HCWs may more explicitly lack compliance than others. For example, despite continued exposure to bodily fluids through PIs, EMS providers do not regularly follow SPs [21, 22].

There are some factors contributing to failure of compliance with SPs among HCWs. HCWs, including EMS providers, are often known to have risk-taking personalities, are subjected to extraordinarily high demands regarding work, and may rush to complete their tasks [20]. In addition, fatigue and prolonged shift duration is a common concern among EMS providers and is an additional contributing factor to lower implementation of SPs [23, 24, 25, 26]. Fortunately, EMS providers exposed to feedback and appropriate training increased selfreporting and compliance with SPs by 50\% [27].

\section{Research Need}

Considering all occupational exposure concerns, it is important to focus on pre-hospital and in-hospital providers regarding the risk of occupational exposure to body fluids and other harmful pathogens during performance of their work. In addition to what we mentioned above regarding the increased level of infectious disease, rural areas had a 114\% increase in acute HBV from 2006-2013 [28] and significant increases in cases 
of acute $\mathrm{HCV}$ among persons aged $\leq 30$ years [29]. In pre-hospital, EMS providers are at a high risk of exposure to contagious diseases from blood borne viruses and other sources of potential infection [10]. In rural areas, previous studies show increased levels of fatigue, reduced sleep, and encountered violence among EMS

providers [30, 31], alongside the urgent need for intervention among HCWs in rural areas due to the significant PI and exposure to other pathogens [31]. Therefore, HCWs, including EMS providers, function in a unique environment that exposes them to bodily fluids in both urban and rural areas. There is, however, little to no research regarding occupational exposure to bloodborne pathogens among EMS providers specifically in rural areas.

\title{
5.1.Statement of Problem
}

The objective of this dissertation is to evaluate occupational exposure to blood and bodily fluids among HCWs. The central hypothesis of this proposal is that HCWs, including EMS providers, will have increased levels of occupational exposure to bodily fluids.

\subsection{Specific Aims}

The objectives of the dissertation are as follows:

\begin{abstract}
Aim 1:
objective 1 =To assess the extent of knowledge, consistency, and practice of SPs.

It is important to have broad view of occupational health and safety to determine unknown factors and other aspects that might be hidden or abandoned in the field of EMS. Accordingly, the survey will provide us with better knowledge of occupational health and safety and will help to establish better training programs and
\end{abstract} policies.

objective 2 ; To assess the knowledge of EMS providers regarding needlestick injuries.

Occurrences of needlestick injuries will be assessed for both urban and rural areas. Knowing characteristics of EMS providers regarding needlestick injuries in both areas will help us understand the 
magnitude and the risk of this issue, hopefully encouraging policy makers, organizations, and EMS leaders to take an action to prevent further risk among EMS providers.

\section{Aim 3: To evaluate blood and bodily fluids exposure incidents among HWCs.}

Blood and body fluids exposure incidents will be retrieved from hospital records. This aim will be to track incidents that occurred from 2014 to 2017. This goal of this aim is to provide us with general knowledge and understanding of the characteristics of HCWs in a hospital regarding types of exposure incidents. Accordingly, results will help us in bridging strong communications between occupational health and policy makers regarding SPs and risk prevention.

\subsection{Significance}

Lack of SPs compliance among EMS providers means that they often encounter infections that go unobserved in their ardent attempt to save lives. It is crucial to assess their knowledge and awareness of SPs to attain the optimal level of safety. Best practices, an understanding of infectious diseases, and ethical implications are the best solutions for preventing such infections. This dissertation focuses on assessing the knowledge of HCWs, including EMS providers, around SPs through various means of prevention. In fact, little to no studies have been performed to precisely measure their knowledge around this topic, specifically in rural areas. Consequently, the dissertation will assess the need for continuing education to prevent occupational hazards such as infection and determine what characteristics of HCWs are most likely to lead to exposure.

\subsection{Innovation}

This dissertation includes both pre-hospital and in-hospital providers, like HCWs in hospitals and EMS providers. It will help enhance the occupational health and safety both in-hospital and out of hospital in both

urban and rural areas. Based on the CDC's SPs, EMS providers will be assessed to determine the strengths and 
weakness of their knowledge. Furthermore, HCWs will be assessed regarding exposure incidents. Results will

allow the development of appropriate programs to enhance safety practice in the health field.

\section{References}

1. Centers for Disease Control and Prevention (CDC). (2017). Bloodborne infectious diseases: HIV/AIDS, hepatitis B, hepatitis C. Last updated April 5, 2017. Retrieved on October 28, 2017, from https://www.cdc.gov/niosh/topics/bbp/default.html

2. Centers for Disease Control and Prevention (CDC). (2010). Sticks campaign. Last updated September 28, 2010. Retrieved on October 28, 2017, from https://www.cdc.gov/niosh/stopsticks/bloodborne.html

3. Centers for Disease Control and Prevention (CDC). (2016). HIV/AIDS. Retrieved on October 28, 2017, from https://www.cdc.gov/hiv/basics/statistics.html

4. Centers for Disease Control and Prevention (CDC). (2016). Viral hepatitis surveillance: United States, 2015. Retrieved on October 28, 2017, from https://www.cdc.gov/hepatitis/statistics/2015surveillance/index.htm

5. Rischetelli, G., Harris, J., McCauley, L., Gershon, R., \& Guidotti, T. (2001). The risk of acquiring Hepatitis B or C among public safety workers: A systematic review. American Journal of Preventive Medicine, 20(4), 299-306.

6. Hämäläinen, P., Takala, J., \& Saarela, K. L. (2007). Global estimates of fatal work-related diseases. American Journal of Industrial Medicine, 50(1), 28-41. doi:10.1002/ajim.20411

7. Kuhar, D. T., Henderson, D. K., Struble, K. A., Heneine, W., Thomas, V., \& Cheever, L. W. (2013). US Public Health Service Working Group: Updated US public health service guidelines for the management of occupational exposures to human immunodeficiency virus and recommendations for postexposure prophylaxis. Infection Control and Hospital Epidemiology, 34(9), 875-892.

8. Luckhaupt, S. E., and Calvert, G. M. (2008). Deaths due to bloodborne infections and their sequelae among health-care workers. American Journal of Industrial Medicine, 51, 812-824.

9. Tomkins, S. E., Elford, J., Nichols, T., Aston, J., Cliffe, S. J., Roy, K., ... \& Ncube, F. M. (2012). Occupational transmission of hepatitis $\mathrm{C}$ in healthcare workers and factors associated with seroconversion: UK surveillance data. Journal of Viral Hepatitis, 19(3), 199-204.

10. Centers for Disease Control and Prevention (CDC). (2015). Sharps safety for healthcare settings. Retrieved on October 28, 2017, from https://www.cdc.gov/sharpssafety/index.html

11. Heick, R., Young, T., \& Peek-Asa, C. (2009). Occupational injuries among emergency medical service providers in the United States. Journal of Occupational and Environmental Medicine, 51, 963-968.

12. Boal, W., Leiss, J., Ratcliffe, J., Sousa, S., Lyden, J., Li, J., \& Jagger, J. (2010). The national study to prevent blood exposure in paramedics: Rates of exposure to blood. International Archives of Occupational and Environmental Health, 83(2), 191-199.

13. Chen, G. X., \& Jenkins, E. L. (2007). Potential work-related exposures to blood borne pathogens by industry and occupation in the United States Part II: A telephone interview study. American Journal of Industrial Medicine, 50, 285-292.

14. Centers for Disease Control and Prevention (CDC). (1987). Recommendation for prevention of HIV transmission in health-care settings. Morbidity and Mortality Weekly Report, 36(2), 1-18.

15. Jagger, J., Perry, J., Gomaa, A., \& Phillips, E. K. (2008). The impact of U.S. policies to protect healthcare workers from bloodborne pathogens: The critical role of safety engineered devices. Journal of Infection and Public Health, 1, 62-71. 
16. Occupational Safety and Health Administration. (1991). Occupational exposure to bloodborne pathogens. Final Rule. Federal Register: 56(235), 64004-64182.

17. Occupational Safety and Health Administration. (2001). Occupational exposure to bloodborne pathogens: Needlestick and other sharps injuries; Final rule. 29 CFR Part 1910. Supplementary information; Part III: Summary and explanation. Federal Register, 66(12), 5318-5325.

18. Hosoglu, S., Akalin, S., Sunbul, M., Otkun, M., \& Ozturk, R. (2011). Healthcare workers' compliance with universal precautions in turkey. Medical Hypotheses, 77(6), 1079-1082. doi:10.1016/j.mehy.2011.09.007

19. Pereira, F. M. V., Lam, S. C., Chan, J. H. M., Malaguti-Toffano, S. E., \& Gir, E. (2015). Difference in compliance with standard precautions by nursing staff in Brazil versus Hong Kong. American Journal of Infection Control, 43(7), 769.

20. Pereira, F. M. V., Malaguti-Toffano, S. E., da Silva, A. M., Canini, Silvia Rita Marin da Silva, \& Gir, E. (2013). Adherence to standard precautions of nurses working in intensive care at a university hospital. Revista Da Escola De Enfermagem Da U S P, 47(3), 686.

21. Bledsoe, B. E., Sweeney, R. J., Berkeley, R. P., Cole, K. T., Forred, W. J., \& Johnson, L. D. (2014). EMS provider compliance with infection control recommendations is suboptimal. Prehospital Emergency Care, 18(2), 290-294.

22. Harris, S. A., \& Nicolai, L. A. (2010). Occupational exposures in emergency medical service providers and knowledge of and compliance with universal precautions. AJIC: American Journal of Infection Control, 38(2), 86-94. doi:10.1016/j.ajic.2009.05.012

23. Fisman, D. N., Harris, A. D., Rubin, M., Sorock, G. S., \& Mittleman, M. A. (2007). Fatigue increases the risk of injury from sharps devices in medical trainees: Results for a case-crossover study. Infection Control and Hospital Epidemiology, 28(1), 10-17.

24. Sofianopoulos, S., Williams, B., Archer, F., Thompson, B. (2011). The exploration of physical fatigue, sleep and depression in paramedics: A pilot study. Journal of Emergency Primary Health Care, 9(1), 990435.

25. Patterson, P. D., Suffoletto, B. P., Kupas, D. F., Weaver, M. D., \& Hostler, D. (2010). Sleep quality and fatigue among prehospital providers. Prehospital Emergency Care, 14(2), 187-193.

26. Weaver, M. D., Patterson, P. D., Fabio, A., Moore, C. G., Freiberg, M. S., \& Songer, T. J. (2015). An observational study of shift length, crew familiarity, and occupational injury and illness in emergency medical services workers. Occupational and Environmental Medicine, 72(11), 798-804.

27. Eliseo, L. J., Murray, K. A., White, L. F., Dyer, S., Mitchell, P. A., \& Fernandez, W. G. (2011). EMS providers' perceptions of safety climate and adherence to safe work practices. Prehospital Emergency Care, 16(1), 53-58.

28. Harris, A. M., Iqbal, K., Schillie, S., et al. (2016). Increases in acute hepatitis B virus infections-Kentucky, Tennessee, and West Virginia, 2006-2013. Morbidity and Mortality Weekly Report, 65.

29. Zibbell, J. E., Iqbal, K., Patel, R. C., Suryaprasad, A., Sanders, K. J., Moore-Moravian, L., ... \& Holtzman, D. (2015). Increases in hepatitis $C$ virus infection related to injection drug use among persons aged $\leq 30$ years-Kentucky, Tennessee, Virginia, and West Virginia, 2006-2012. Morbidity and Mortality Weekly Report, 64(17), 453-458.

30. Pyper, Z., \& Paterson, J. L. (2016). Fatigue and mental health in Australian rural and regional ambulance personnel. Emergency Medicine Australasia, 28(1), 62-66.

31. Gormley, M. A., Crowe, R. P., Bentley, M. A., \& Levine, R. (2016). A national description of violence toward emergency medical services personnel. Prehospital Emergency Care: Official Journal of the National Association of EMS Physicians and the National Association of State EMS Directors, 20(4), 439.

32. Ngatu, N. R., Phillips, E. K., Wembonyama, O. S., Hirota, R., Kaunge, N. J., Mbutshu, L. H., .. . \& Suganuma, N. (2012). Practice of universal precautions and risk of occupational blood-borne viral infection among Congolese health care workers. American Journal of Infection Control, 40(1), 68.

doi:10.1016/j.ajic.2011.01.021 


\section{CHAPTER 2: Standard Precautions among Emergency Medical Services in Urban and Rural Areas}

\section{INTRODUCTION}

Blood and body fluids contain an extensive variety of microbes and pathogens that cause harm to people. This harm includes the transmission of infectious diseases. Exposure to blood and other bodily fluids occurs across a wide variety of occupations, including EMS. EMS involve well-organized procedures and various actions for life support. EMS providers deliver pre-hospital care to patients and therefore have significant potential for pathogen transmission, especially in the case of severe injuries and illness. ${ }^{1}$ EMS providers are often exposed to blood and body fluids, resulting in concerns regarding transmission of bloodborne and airborne pathogens..$^{2,3}$

EMS providers are frequently exposed to blood and bodily fluids through percutaneous injuries (PIs). ${ }^{2}$ The rate of PIs among EMS providers is higher than most hospital-based health care workers (HCWs) in United States. ${ }^{4.5}$ A previous study of EMS providers in Rhode Island from 1995 to 2001 estimates $34 \%$ of occupational injuries were associated with PIs. ${ }^{6}$ Furthermore, $15 \%$ of occupational injuries were associated with PIs from 2003 to 2007 nationally. ${ }^{7}$ In contrast, a study finds exposure associated with non-intact skin is higher than other routes of exposure among EMS providers. ${ }^{4}$ Prolonged shift duration contributes to occupational injury and illness among EMS providers. ${ }^{8}$ An Australian report finds that $92 \%$ of EMS providers reported being fatigued at work, and $88 \%$ expressed that fatigue affected their job performance. ${ }^{9}$ In fact, a 2012 study finds an association between sleep quality, fatigue, and safety outcomes of EMS providers. ${ }^{10}$ 
There are a number of regulations and standards supporting occupational safety among HCWs, including EMS providers. ${ }^{11}$ The Centers for Disease Control and Prevention (CDC) and the United States Occupational and Safety and Health Administration (OSHA) promotes standards to reduce the risk of exposure among HCWs. Standard Precautions (SPs), previously called Universal Precautions (UPs), were introduced in response to the emergence of the human immunodeficiency virus (HIV) in the 1980s. ${ }^{11}$ Implementation of SPs is the main strategy preventing transmission of bloodborne and airborne pathogens among patients and HCWs. The principle of SPs is that all HCWs are easily exposed to blood, body fluid secretions, non-intact skin, or mucous membranes that may contain infectious pathogens, and SPs protect them from possible exposure. ${ }^{12}$ Later, the Needlestick Safety and Prevention Act of 2000 built upon the original SPs by including more aspects of infection control. ${ }^{13}$ These efforts by OSHA and the CDC have resulted in well-developed and defined regulations regarding prevention of bloodborne pathogen exposure and needlestick injuries.

Despite continued exposure to blood and bodily fluids, studies show that EMS providers who were exposed to blood and body fluids have inconsistently used SPs. ${ }^{14.15}$ Continued training decreases the occupational exposure among EMS providers. Therefore, EMS providers with ongoing and appropriate training have increased self-reporting and compliance with safe work practices by $50 \% .{ }^{16}$ Furthermore, studies find sufficient provision of SPs would have reduced the occupational risk of needlestick injuries and non-intact skin exposure among EMS providers. ${ }^{17.18 .19}$ The effective use of SPs, combined with adequate training, would have reduced blood and body fluids exposure among EMS providers. ${ }^{17,18}$ Authors stress EMS providers must use the effective SPs on every patient irrespective of the patient's condition. ${ }^{3}$ Generally, there is an urgent need for intervention among HCWs in rural areas to reduce IPs. ${ }^{20}$ EMS providers face increased levels of fatigue, reduced sleep, and encountered violence in rural areas. ${ }^{21,22}$ Thus, due to the significant PIs and exposure to other pathogens, there is little to no research regarding EMS providers' compliance and knowledge on SPs in rural areas. The objective of this study was to assess the extent of knowledge, consistency, and practices of SPs and to explore characteristics of rural and urban EMS providers that predicted lacking compliance with SPs. 


\section{METHODS}

\subsection{Study Design and Population}

This project was a cross-sectional survey conducted with a simple random sample of certified EMS providers in West Virginia. An invitation email was sent to randomly selected EMS agencies from a comprehensive list of agencies from the Office of West Virginia Emergency Medical Services. Six out of twelve different agencies replied and agreed to participate in distributing the survey link to their membership. The entire pool of certified EMS providers of these agencies was 522 EMS providers, varying from critical care paramedics, paramedics, Emergency Medial Technician (EMT)-advanced, EMT-basics, and emergency medical responders. Study instructions and an electronic cover letter were shown at the beginning of the survey. This study was approved by the West Virginia University.

\subsection{Survey Instrument}

An existing survey instrument was used on a previous study regarding knowledge, consistency and attitude; and practices of SPs on HCWs. ${ }^{23}$ The survey was modified and reviewed for face validity by an EMT-P and an infectious disease officer at EMS. Based on their feedback, the survey was revised to suit the field of EMS prior to distribution. The survey was pilot-tested on ten EMS providers in multiple areas to assess legibility, to simplify any unclear questions, and to define average time to completion.

The survey consists of four sections: socio-demographic characteristics; knowledge and source of information; consistency and attitude; and the practice and application of SPs.

The first section collected demographics, including age (18-29 years, 30-39 years, 40-49 years, 50-59 years and 60+ years), gender (male and female), and place of residence, defined as urban or rural according to standards used by the US Census Bureau as reported by the United States Office of Management and Budget $(\mathrm{OMB})^{24}$. Urban areas were defined as having a population of over 50,000. Rural areas were defined as having a population of less than 50,000. Additional demographics included level of certification (First Responders, 
EMT-Basic, EMT-Intermediate, Paramedics and Critical Care Paramedics), employment status (full-time, parttime and volunteer) and years of service ( $<5$ years, 6-10 years, $11-15$ years, and $>15$ years).

The second section was to assess the EMS providers' knowledge of the purpose of SPs. In this section, adequate knowledge was assessed by asking participants to choose the most appropriate option, which is "to protect myself and my patient from blood borne and airborne infection." Accordingly, any other option chosen does not include this option, it is considered as inadequate knowledge.

The third section asked about EMS providers' consistency and attitude toward SPs. EMS providers were asked whether or not to use SPs on every patient. Participants who answered "sometimes" or "never" in response were automatically directed to a new question where they were asked for an explanation of why they do not use SPs on every patient.

The fourth section was focused on the practice and application of SPs. EMS providers were asked about the measures taken to avoid contact with blood and body fluids. The best practice was assessed by selecting the most appropriate option, which is "wear gloves, wash hands regularly, avoid recapping needles, dispose of sharps in appropriate sharps container, and wear mask/eye protection.” Consequently, any other option chosen was considered suboptimal. The fourth section also asked about disposal methods of sharp needles and what barriers prevented them from following SPs (inadequate supplies, insufficient funds, etc.).

\subsection{Survey Data Collection}

The web-based survey was administered using the secure, online software Qualtrics ${ }^{24}$ via link sent to EMS agency directors in West Virginia. Certified EMS providers who were currently working in West Virginia and over eighteen years old were included and eligible to complete the anonymous online survey.

The web link to the online survey was active for 30 days from the time of sending out an email to EMS directors, and two reminder emails were sent. The EMS provider received the email and opened the hyperlink, which automatically took them to the website. At the beginning of the online survey, a general description of 
the study and the cover letter was provided to each respondent. After participants elected to take the survey, survey questions became available.

\subsection{Data Analysis}

Data analysis was performed using Statistical Analysis System (SAS) software, Version 9.4. Descriptive statistics were performed first to summarize EMS providers' demographic characteristics, including summary tables, box-plots, frequencies, and proportions. Then, a chi-square test was used to compare categorical variables. All findings are reported using 95\% confidence intervals (CIs). Furthermore, a logistic regression (adjusted model) was used to explain the relationship between independents and outcome. Odds ratios (ORs) and $95 \%$ confidence intervals (CIs) were estimated. Differences at the $\alpha=0.05$ level were considered statistically significant.

\section{RESULTS}

\subsection{Demographic Characteristics}

A total of 248 out of $522(47,50 \%)$ EMS providers completed the survey. 167 (67.3\%) were male, and $81(32.7 \%)$ were female. The majority of the EMS providers $(194,78.2 \%)$ reported working in rural areas, whereas $54(21.8 \%)$ working in urban areas. The majority of EMS providers were full time $(222,89.5 \%)$; however, part time and volunteer totaled $24(9.7 \%)$ and $2(0.8 \%)$, respectively. Most ages of EMS providers were between 18 and $29(84,33.9 \%)$ and then between 30 and $39(82,33.1 \%)$, followed by 60 and above (6, 2.4\%). A majority of EMS providers' certifications were EMT-Basic (108, 43.5\%), followed by paramedics $(80,32.2 \%)$, while only $9(3.6 \%)$ were first responders. $88(35.5 \%)$ of EMS providers reported having less than 5 years of experience in EMS, followed by more than 15 years $(70,28.3 \%)$ (Table1). 


\subsection{Knowledge of Standard Precautions}

Table 2 describes responses of the EMS providers' knowledge of the purpose of use the SPs. The majority of the EMS providers (93.5\%) included and identified the most appropriate answer, "To protect myself and my patient from bloodborne and airborne infections," which was categorized as adequate knowledge of SPs. Therefore, 232 (93.5\%) of EMS providers had adequate knowledge of SPs, while $16(6.5 \%)$ had inadequate knowledge of SPs.

A chi-square tests were used to evaluate the relationship between knowledge of the purpose of SPs and demographics (Table 3). There was a statistically significant association between employment status and knowledge of SPs (p-value [p] =0.01). 50.0\% of volunteer EMS providers had inadequate knowledge of SPs, while only $12.5 \%$ of part-time and $5.41 \%$ of full-time EMS providers had inadequate knowledge of the purpose of SPs.

Table 4 illustrates the results of the adjusted logistic regression model for knowledge of SPs and demographics. Among age groups, the ages of 40-49 were referenced. Hence, the odds of having inadequate knowledge of SPs among EMS providers who were between the ages of 18-29 was 0.12 times less than those who were between the ages of 40-49 (odds ratio $[\mathrm{OR}]=0.12,95 \% \mathrm{CI}=0.01-0.82, \mathrm{p}=0.03$ ). In employment status, the odds of having inadequate knowledge of SPs among EMS providers who worked part-time were 7.39 times more EMS providers who worked full-time( $\mathrm{OR}=7.39, \mathrm{CI}=1.51-35.36, \mathrm{p}=0.01)$.

Stratification methods were used to assess the relationship between residence and genders in regards to knowledge of SPs. Figure 1 displays gender with knowledge of SPs among stratified residence. Figure 1 shows varying proportion of inadequate knowledge of SPs among males (7.3\%) and female (23.1\%) in urban areas. However, there was no statistically significant association between gender and knowledge of SPs in urban areas $(\mathrm{OR}=3.8, \mathrm{CI}=0.66-21.77, \mathrm{p}=0.14)$ as well as gender and knowledge of $\mathrm{SPs}$ in rural areas $(\mathrm{OR}=0.19, \mathrm{CI}$ $=0.02-1.57, \mathrm{p}=0.17)$. Knowledge of SPs was tested to assess the relationship with gender among stratified residence (Figure 1). The odds of having adequate knowledge of SPs among female EMS providers who 
worked in urban areas were 0.05 times less than female providers who worked in rural areas. So, there was a statistically significant association between residence and knowledge among females $(\mathrm{OR}=0.05, \mathrm{CI}=0.005$ 0.53, $\mathrm{P}=0.01)$. Specifically, there were varying proportions of inadequate knowledge of SPs among female EMS providers who worked in urban areas $(23.1 \%)$ and rural areas $(1.5 \%)$.

\subsection{Consistency with Standard Precautions}

Figure 2 demonstrates responses of the EMS providers' attitude toward the use of SPs on every patient. The majority of the EMS providers answered "always" (76.61\%) in response to whether or not they consistently followed SPs, 23.39\% answered "sometimes," and 0\% answered "never." The "never" choice was removed from the analysis, since no participants chose it.

Chi-square tests were used to evaluate the relationship between consistent compliance with SPs and demographics of the EMS providers (Table 3). There was a statistically significant association between residence and consistent compliance of the use of SPs $(\mathrm{p}=0.01) .38 .89 \%$ of urban EMS providers responded that they "sometimes" used SPs, while only $19.07 \%$ of rural EMS providers responded with "sometimes." Additionally, there was a statistically significant association between age and consistent compliance of the use of SPs ( $\mathrm{p}=0.03)$. EMS providers at age 60 years and older $(66.66 \%)$ were the highest proportion among age groups, followed by ages 40-49 (29.41\%), 50-59 (28.00\%), and 30-39 (23.17\%) respectively. Years of experience were statistically associated with consistent compliance of the use of SPs $(\mathrm{p}=0.01)$. More specifically, EMS providers with more than 15 years of experience $(43.29 \%)$ were the highest proportion of "sometimes" responses compared to EMS providers with 11-15 years (32.35\%) and 6-10 years (17.85\%) of experience.

Table 5 illustrates the results of the adjusted logistic regression model for consistent compliance of the use of SPs. In residence, the odds of choosing "sometimes" among EMS providers who worked in rural areas 
were 0.38 times less than those who worked in urban areas $(\mathrm{OR}=0.38, \mathrm{CI}=0.18-0.78, \mathrm{p}=0.008)$. There were no variables with significant association with consistent compliance of the use of SPs, controlling the covariates.

Stratification methods were performed to assess the relationship between residence and genders in regards to consistent compliance of the use of SPs. Figure 3 shows gender and consistent compliance of the use of SPs among stratified residence. Figure 3 shows varying proportion in "sometimes" responses among males (43.90\%) and females $(23.10 \%)$ in urban areas. Consistent compliance of SPs was assessed to see the relationship with genders among stratified residence (Figure 3). The odds of responding "always" among male EMS providers who worked in urban areas were 0.33 times less than those who worked in rural areas. So, there was a statistically significant association between residence and knowledge among males $(\mathrm{OR}=0.33, \mathrm{CI}=0.16$ $0.71, \mathrm{p}=0.01)$. Specifically, there was a varying proportion of "sometimes" responses among male EMS providers who worked in urban areas $(43.90 .1 \%)$ and rural areas $(20.60 \%)$.

Table 6 outlines responses to why participants who responded "sometimes" do not consistently comply with SPs. 52 out of 58 EMS providers who selected a "sometimes" choice answered this question, including 19 $(36.53 \%)$ rural EMS providers and $33(63.47 \%)$ urban EMS providers. The most selected response among all EMS providers was "I only use the SPs on very bad calls" with $59.62 \%$, followed by "I don't have time to use SPs on every patient" with $38.46 \%$. Similarly, rural EMS providers chose similar responses, with $66.67 \%$ and $30.30 \%$ respectively. However, the most selected among urban EMS providers was "I don't have time to use UPs on every patient" with $52.63 \%$, followed by "I only use the SPs on very bad calls."

\subsection{Practice of the Standards Precautions}

Table 7 presents responses to the measures to be taken to avoid contact with blood and body fluids. The most appropriate answer that includes the complete components of SPs is "wear gloves, wash hands regularly, avoid recapping needles, dispose of sharps in appropriate sharps container, wear mask/eye protection and cover open wounds." $30 \%$ of EMS providers selected the complete practice of use of SPs, which was categorized as 
optimal practice, and 70\% of EMS providers chose otherwise, which was categorized as suboptimal practice. A chi-square test was used to test the relationship between the practice of SPs and demographics of the EMS providers (Table 3). There is no variable shown a statistically significant association with the practice of SPs. Table 3 shows each variable had similar proportions within its factors.

Table 8 illustrates the results of the adjusted logistic regression model for practice of SPs and demographics of EMS providers. Within years of experience among EMS providers, the odds of suboptimal practice of SPs among EMS providers who had 11-15 years of experience were 3.50 times more than those who had less than 5 years of experience $(\mathrm{OR}=3.50, \mathrm{CI}=1.127-11.85, \mathrm{p}=0.03)$. Furthermore, the odds of suboptimal practice of SPs among the EMS providers who had 15 or more years of experience were 3.12 times more than those who had less than 5 years $(\mathrm{OR}=3.12, \mathrm{CI}=1.044-9.62, \mathrm{p}=0.04)$.

Stratification methods were used to assess the relationship between residence and genders in regards to the practice of SPs. Figure 4 shows gender with practice of SPs among stratified residence. There was no statistically significant association between gender and the practice of SPs in urban areas $(\mathrm{OR}=0.32, \mathrm{CI}=0.088$ 1.23, $\mathrm{p}=0.15)$. Similarly, gender with practice of $\mathrm{SPs}$ in urban areas $(\mathrm{OR}=0.87, \mathrm{CI}=0.46-1.64, \mathrm{p}=0.74)$ was not statistically significant. Practice of SPs was tested to see the relationship with genders among stratified residence (Figure 4). There was no association between urban areas (78.1\%) and rural areas (70.6\%) among males $(\mathrm{OR}=0.68, \mathrm{CI}=0.29-1.56,0.42)$. Also, there was no association between urban areas $(53.8 \%)$ and rural areas $(67.7 \%)$ among females $(\mathrm{OR}=1.79, \mathrm{CI}=0.54-5.97,0.35)$.

The practice of disposal of sharp objects was assessed. Consequently, 99\% of EMS providers selected to dispose the sharp objects in specific sharp containers. Table 9 shows the barriers that prevented participants from the use of SPs. 117 EMS providers answered this question, with $21.37 \%$ in urban areas and $76.63 \%$ in rural areas. "Inadequate supply of mask and eye protection" was the most selected option overall (33.33\%). This option was also the highest ranking in urban areas (36.00\%), but not in rural areas (32.61\%). "Difficulty in receiving restocking supplies" was the second-most selected option overall $(30.77 \%)$, but it was the highest 
ranking in rural areas (35.86\%). "Inadequate supply of gloves" was the third-most selected option overall (15.38\%), and it was the second-highest ranking in urban areas $(20.00 \%)$.

\section{DISCUSSION}

EMS providers are at a high risk for occupational exposure to contagious diseases and are frequently exposed to blood and body fluids. ${ }^{2,3}$ This study evaluated the extent of knowledge, consistency, and practices of SPs among EMS providers in urban and rural areas despite well-developed and defined regulations and the implementation of SPs as recommended by the CDC and OSHA. ${ }^{11,13}$ In this project, 248 of $5.22(47.50 \%)$ targeted EMS providers completed a cross-sectional survey. The goal of this study was to identify possible areas of improvement in the area of occupational health and safety for both urban and rural EMS providers.

\subsection{Knowledge of Standard Precautions}

The majority of the EMS providers had an adequate knowledge of the purpose of SPs, and only $6.5 \%$ had an inadequate knowledge of the purpose of the SPs. These results are in contrast to previous study, where a majority of EMS providers were found to have an inadequate knowledge of SPs. ${ }^{15}$ This difference in results may be explained by differing definitions of the knowledge of SPs, as the previous study focused on the knowledge of components of SPs among EMS providers. In contrast, this study focused on the knowledge of general purpose of the SPs. In our project, most EMS providers successfully defined the purpose of SPs. There was no a relationship between the levels of certification and knowledge of SPs in this study, in contrast to the Harris \& Nicolai's study that shows more highly certified EMS providers were more inclined to successfully identify the components of SPs. ${ }^{15}$

Residence showed no relationship with knowledge of SPs; the EMS providers in both urban and rural areas tended to correctly identify the purpose of SPs. This lack of relationship may be attributed to the survey responders receiving the same level of education, including occupational health and safety, in both urban and 
rural areas. Previous study emphasized the urgent use of SPs among EMS providers who work in urban areas due to a high rate of infectious diseases. ${ }^{3}$ However, there was a relationship between employment status and knowledge of SPs. Through multivariable analysis (Table 4), we found that EMS providers who worked parttime have extremely inadequate knowledge of the purpose of SPs compared to full-time EMS providers, after combining volunteers with part-time EMS providers due to low sample size of total volunteers ( $\mathrm{n}=2$ ). By using stratification methods with residence and gender, we found that female EMS providers who work in urban areas are less knowledgeable of SPs than female EMS providers in rural areas, but male EMS providers had the same level of knowledge of SPs in both areas.

\subsection{Consistency with Standard Precautions}

In this study, $76.61 \%$ of EMS providers always use SPs on every patient, and only $23.39 \%$ inconsistently use SPs, meaning most EMS providers comply with SPs recommendations. Harris \& Nicolai addressed different findings regarding the compliance of SPs. In their study, they found that a majority of EMS providers' inconsistently used SPs. However, the study was conducted in Virginia, which includes larger counties where EMS providers might be prone to larger numbers of patients. Accordingly, EMS providers might be more subject to neglecting SPs recommendations. ${ }^{15}$ Bledsoe et al also demonstrated that most EMS providers inconsistently comply with SPs. Bledsoe et al.'s study was based on prospective observation, where EMS providers were watched when arriving at emergency departments. ${ }^{14}$ Therefore, the study was based on an observed evidence, which was a different approach from this study.

In this study, we found a relationship between residence and consistent compliance of SPs. Urban EMS providers comprised a greater percentage of participants who inconsistently use SPs (39\%) compared to rural EMS providers (19\%). There were no previous studies showing the difference between urban and rural EMS providers regarding occupational health and safety. Presumably, faster rhythms of life and greater demands in urban areas might play a role in explaining this varying proportion of compliance of SPs among EMS providers. 
Age and years of experience of EMS providers were associated with consistent compliance of SPs.

Older and the more experienced EMS providers showed less compliance with SPs. In contrast to a previous study, age and years of experience did not show any association with exposure to blood exposure due to noncompliance of SPs. ${ }^{4}$ Our findings generally show that there is no association between gender and inconsistent compliance of SPs. However, Boal et al found that there is a relationship between gender and non-intact skin exposure to blood due to non-compliance of SPs. Specifically, males are more often exposed to non-intact skin than females, meaning female EMS providers show better compliance with SPs. ${ }^{4}$

In multivariable analysis, the only variable we found significantly associated with compliance of SPs is residence, where EMS providers who worked in rural areas were showed extremely inconsistent use of SPs comparable to EMS providers in urban areas $(\mathrm{OR}=0.38, \mathrm{CI}=0.18-0.78, \mathrm{p}=0.008)$. Accordingly, when stratifying gender and residence based on the consistency with SPs, these findings support what Boal et al found regarding that males are more likely than females inconstantly comply with SPs. ${ }^{4}$ The compliance of SPs and gender in urban areas were assessed and varying proportions of inconsistent compliance were found.

Specifically, we found males (43.90\%) show much higher inconsistent compliance with SPs than females $(23.10 \%)$ in urban areas, but not in rural areas. In addition, males in urban areas (43.90\%) are much more inconsistently compliant with SPs than males in rural areas $(20.60 \%)$.

The EMS providers who chose that they "sometimes" comply with SPs answered an extra question about why they do not use the SPs consistently. In general, most EMS providers responded that they only use SPs on very bad calls. Fewer participants selected "I don't have time to use UPs on every patient." Most urban EMS providers selected "I don't have time to use UPs on every patient," and most rural EMS providers selected "I only use the SPs on very bad calls." There are some circumstances, which would explain why EMS providers in different areas selected different answers. The higher demand for EMS providers and many requests for transfer would make the use of SPs among urban EMS providers difficult to consistently follow. Additionally, EMS providers in urban areas might face insufficient supplies of SPs due to many requests for EMS providers. 
On the other hand, a lower demand for EMS providers and therefore an infrequent need for SPs could cause inconsistent compliance among EMS providers in rural areas except for really bad cases.

\subsection{Practice of Standards Precautions.}

SPs are recommended to be applied to all patients in EMS and healthcare settings. These practices include hand hygiene; use of personal protective equipment (PPE) such as gloves, gowns, masks, eye protection, and face shields; and safety engineering practices such as disposing of sharps in appropriate containers, avoiding recapping needles, and covering open wounds. ${ }^{12} \mathrm{We}$ did not consider the use of gowns or the disinfection of ambulances as SPs in this study; however, this practice is most likely part of complete precaution in EMS settings.

As shown in Table 7, most EMS providers showed a suboptimal practice of SPs by selecting an inconsistent practice of SPs, and only $30 \%$ of respondents showed optimal practice of SPs. The most selected response was suboptimal practice: "wear gloves, wash hand regularly, avoid recapping needles, dispose of sharps in appropriate sharps container, and cover open wounds." This selection missed crucial components of the practice of SPs, specifically masks and eye protection. Those who selected this option include $48.40 \%$ among all EMS providers and $68.97 \%$ among those who showed suboptimal practice. EMS providers mainly transfer critically ill or injured patient expeditiously to emergency departments, and those EMS providers who selected this choice would probably pick the easy and fast practice of SPs. Mathews .et al found that some EMS providers ineffectively follow the complete practice of SPs because they are inadequately trained as well as the use of some components can limit their ability to care for their patients. ${ }^{19}$ In addition, A Bledsoe .et al found that most EMS providers do not consistently use SPs, especially the use of gloves and hand washing practices; they found that only $56.9 \%$ of EMS providers arrived to the emergency department wearing gloves and only $27.80 \%$ washed their hands following patient contact. ${ }^{14}$ This study included wearing gloves and washing hands in every 
choice, so we do not have enough information regarding whether or not EMS providers use every component of SPs.

In this sample, a majority of EMS providers showed suboptimal practice of SPs, and there is no specific variable that can be related to the practice of SPs. As shown in Table 3, there is no variable that had a statistically significant association with the practice of SPs, where each variable had similar proportions within its factors. In multivariable analysis, the only variable we found significantly associated with practice of SPs is years of experience, where EMS providers with 11-15 years of experience and more than 15 years of experience showed more suboptimal practice of SPs compared to those with less than 5 years of experience $(\mathrm{OR}=3.50$, $\mathrm{CI}=1.127-11.85, \mathrm{p}=0.03, \mathrm{OR}=3.12, \mathrm{CI}=1.044-9.62, \mathrm{p}=0.04$ respectively). We can presume that EMS providers can adapt to certain parts of the practice of SPs over time until they become part of their primary practice, meaning that the more years they work, the less they practice SPs. This study inducates there is a need for evaluating what components of SPs are used frequently. Furthermore, there is a need for increased use of all of SPs through proper training programs to encourage the use of SPs for every call and case.

Adequate provision and consistent use of SPs can help reduce the intense rate of occupational exposure to blood and body fluids among EMS providers. Some studies suggest sufficient provision of SPs would help in improving occupational health and safety of EMS providers. ${ }^{17,18,19}$ Table 9 shows the barriers to the use of SPs in both urban and rural areas. We found a certain degree of inadequate provisions, such as the supply of masks, eyes protection, and gloves in both urban and rural areas. Additionally, we found that EMS providers in rural areas had difficulty receiving restocking supplies. This study suggests SP supplies should be increased. Future research should evaluate the difference between urban and rural areas in terms of what types of SP supplies are needed as well as investigate how fast suppliers can re-supply insufficiently available items.

\subsection{Limitations}

This study has some potential limitations. First, comparisons with other studies might be limited because the definitions of SPs were different. For example, this study focuses on the knowledge of SPs as a general 
knowledge of the purpose of SPs. In contrast, previous studies focused on defined the knowledge of SPs as knowledge of the components of $\operatorname{SPs}^{15}$. Second, the response rate of $47.50 \%$ created the potential for nonresponse bias, resulting in different findings. For example, EMS providers who are knowledgeable of, consistently compliant with, or optimally practice SPs tended to respond, and others who are less may have tended to be non-responsive to the survey. Third, this study was limited to one state (West Virginia), and the results may not be applicable to other states. Lastly, it was impossible to categorize all EMS agencies as urban or rural because some agencies include stations and squads in different locations. While the definition of place of residence was defined and explained to EMS providers as defined by OMB, some EMS providers may have specified the residence incorrectly, either because of the lack of knowledge concerning their work location or frequent transfer between EMS agencies.

\section{CONCLUSION}

This study of knowledge, consistent compliance, and practice of SPs among EMS providers indicates female EMS providers who work in urban areas are less knowledgeable of SPs than female EMS providers in rural areas, while male EMS providers have the same level of knowledge of SPs in both urban and rural areas. However, EMS providers who work in rural areas showed extremely inconsistent use of SPs compared to EMS providers in urban areas. In addition, most EMS providers show a suboptimal practice of SPs generally in both areas. Our findings emphasize the need of enhanced quality of safe work practices among EMS providers in both areas, and further research is needed to assess urban and rural EMS safe work culture. 


\section{REFERENCES}

1. Mencl, F., Birkle, M., Blanda, M., \& Gerson, L. W. EMTs' knowledge regarding transmission of infectious disease. Prehospital Emergency Care. 2000; 4(1): 57-61.

2. Heick, R., Young, T., and Peek-Asa, C. Occupational injuries among emergency medical service providers in the United States. Journal of Occupational and Environmental Medicine. 2009; 51(8):963-968.

3. Sayed, M. E., Kue, R., McNeil, C., \& Dyer, K. S. A descriptive analysis of occupational health exposures in an urban emergency medical services system: 2007-2009. Prehospital Emergency Care. 2011;15(4), 506510 .

4. Boal, W., Leiss, J., Ratcliffe, J., Sousa, S., Lyden, J., Li, J., \& Jagger, J. The national study to prevent blood exposure in paramedics: Rates of exposure to blood. International Archives of Occupational and Environmental Health. 2010; 83(2): 191-199.

5. Chen, G. X. \& Jenkins, E. L. Potential work-related exposures to blood borne pathogens by industry and occupation in the United States part II: A telephone interview study. American Journal of Industrial Medicine. 2007; 50: 285-292.

6. Merchant, R. C., Nettleton, J. E., Mayer, K. H., \& Becker, B. M. Blood or body fluid exposures and HIV postexposure prophylaxis utilization among first responders. Prehospital Emergency Care. 2009; 13(1): 613.

7. Reichard, A. A., Marsh, S. M, \& Moore, P. H. Fatal and nonfatal injuries among emergency medical technicians and paramedics. Prehospital Emergency Care. 2011; 15(4), 511-517.

8. Weaver, M. D., Patterson, P. D., Fabio, A., Moore, C. G., Freiberg, M. S., \& Songer, T. J. An observational study of shift length, crew familiarity, and occupational injury and illness in emergency medical services workers. Occupational and Environmental Medicine. 2015; 72(11): 798-804.

9. Sofianopoulos, S., Williams, B., Archer, F., \& Thompson, B. The exploration of physical fatigue, sleep and depression in paramedics: A pilot study. J. Emerg. Prim. Health Care. 2011; 9(1).

10. Patterson, P. D., Weaver, M. D., Frank, R. C., Warner, C. W., Martin-Gill, C., Guyette, F. X., \& Hostler, D. Association between poor sleep, fatigue, and safety outcomes in emergency medical services providers. Prehospital Emergency Care. 2012; 16(1): 86-97.

11. Centers for Disease Control and Prevention. Recommendation for prevention of HIV Transmission in Health-care settings. Morbidity and Mortality Weekly Report. 1987; 36(2): 1-18. Retrieved from https://www.cdc.gov/mmwr/preview/mmwrhtml/00023587.htm

12. Siegel, J. D., Rhinehart, E., Jackson, M., \& Chiarello, L. Guideline for isolation precautions: Preventing transmission of infectious agents in healthcare settings 2007. Centers for Disease Control and Prevention. 2007. Retrieved from https://www.cdc.gov/infectioncontrol/guidelines/isolation/index.html

13. Jagger, J., Perry, J., Gomaa, A., \& Phillips, E. K. The impact of U.S. policies to protect healthcare workers from bloodborne pathogens: The critical role of safety engineered devices. Journal of Infection and Public Health. 2008; 1(2): 62-71.

14. Bledsoe, B. E., Sweeney, R. J., Berkeley, R. P., Cole, K. T., Forred, W. J., \& Johnson, L. D. EMS provider compliance with infection control recommendations is suboptimal. Prehospital Emergency Care. 2014; 18(2): 290-294.

15. Harris, S. A. \& Nicolai, L. A. Occupational exposures in emergency medical service providers and knowledge of and compliance with universal precautions. AJIC: American Journal of Infection Control. 2010; 38(2): 86-94.

16. Eliseo, L. J., Murray, K. A., White, L. F., Dyer, S., Mitchell, P. A., \& Fernandez, W. G. EMS providers' perceptions of safety climate and adherence to safe work practices. Prehospital Emergency Care. 2011; 16(1): 53-58.

17. Leiss, J. K. Management practices and risk of occupational blood exposure in U.S. paramedics: Non-intact skin exposure. Annals of Epidemiology. 2009; 19(12): 884-890. 
18. Leiss, J. K. Management practices and risk of occupational blood exposure in U.S. paramedics: Needlesticks. American Journal of Industrial Medicine. 2010; 53(9): 866- 874.

19. Mathews, R., Leiss, J., Boal, W., Lyden, J., Sousa, S., Ratcliffe, J., \& Jagger, J. Provision and use of personal protective equipment and safety devices in the national study to prevent blood exposure in Paramedics. Am J Infect Control. 2008; 36(10): 743-749.

20. Ngatu, N. R., Phillips, E. K., Wembonyama, O. S., Hirota, R., Kaunge, N. J., Mbutshu, L. H., \& Suganuma, N. Practice of universal precautions and risk of occupational blood-borne viral infection among Congolese health care workers. American Journal of Infection Control. 2012; 40(1): 68.

21. Pyper, Z. \& Paterson, J. L. Fatigue and mental health in Australian rural and regional ambulance personnel. Emergency Medicine Australasia. 2016; 28(1): 62-66.

22. Gormley, M. A., Crowe, R. P., Bentley, M. A., \& Levine, R. A national description of violence toward emergency medical services personnel. Prehospital Emergency Care. 2016; 20(4): 439-447.

23. Uchenna, A. P., Johnbull, O. S., Chinonye, E. E., Christopher, O. T., \& Nonye, A. P. The knowledge, Attitude and practice of universal precaution among rural primary health care workers in enugu southeast Nigeria. World J. of Pharmacy and Pharmaceutical Sciences. 2015; 4(9).

24. United States U.S. Census Bureau. Urban and Rural. Census.gov. Retrieved from https://www.census.gov/geo/reference/urban-rural.html Accessed OCT 07, 2017.

25. Qualtrics. About Qualtrics. 2010. Retrieved from http://www.qualtrics.com/about-qualtrics/ 


\section{TABLES and FIGURIES}

Table 2.7.1 : Demographics of EMS

Providers $(\mathrm{n}=248)$

\begin{tabular}{ll}
\hline Characteristics & $\mathrm{n}(\%)$ \\
\hline Gender & $167(67.3)$ \\
Male & $81(32.7)$ \\
Female & \\
Residence & $54(21.8)$ \\
Urban area & $194(78.2)$ \\
Rural area & \\
Age & $84(33.9)$ \\
$18-29$ & $82(33.1)$ \\
$30-39$ & $51(20.6)$ \\
$40-49$ & $25(10)$ \\
$50-59$ & $6(2.4)$ \\
$60+$ & \\
Employment status & $222(89.5)$ \\
Full-time & $24(9.7)$ \\
Part-time & $2(0.8)$ \\
Volunteer & \\
Levels of Certification & $9(3.6)$ \\
First Responders & $108(43.5)$ \\
EMT-Basic & \\
EMT-Intermediate & $14(5.7)$ \\
Paramedics & $80(32.2)$ \\
Critical Care Paramedics & $37(15)$ \\
Years of Experience & \\
$<5$ & $88(35.5)$ \\
$6-10$ & $56(22.6)$ \\
$11-15$ & $34(13.7)$ \\
$>15$ & $70(28.2)$ \\
\hline EMT & Energey Medical Techician
\end{tabular}

${ }^{\mathrm{a}}$ EMT $=$ Emergency Medical Technician 
Table 2.7.2: Knowledge of the Purpose of SPs

\begin{tabular}{ll}
\hline Use of Standard Precautions & $\mathrm{n}(\%)^{*}$ \\
\hline 1. To prevent HIV infection & $169(68)$ \\
2. To prevent needle stick injuries & $134(54)$ \\
3. To prevent airborne infections & $136(55)$ \\
4. To prevent cancer & $51(20.6)$ \\
5.To protect myself and my patient from air/blood borne & \\
infections & $232(93.5)$ \\
\hline & 248 \\
\hline
\end{tabular}


Table 2.7.3 : Relationship between Inadequate Knowledge of SPs and Demographics of EMS Providers

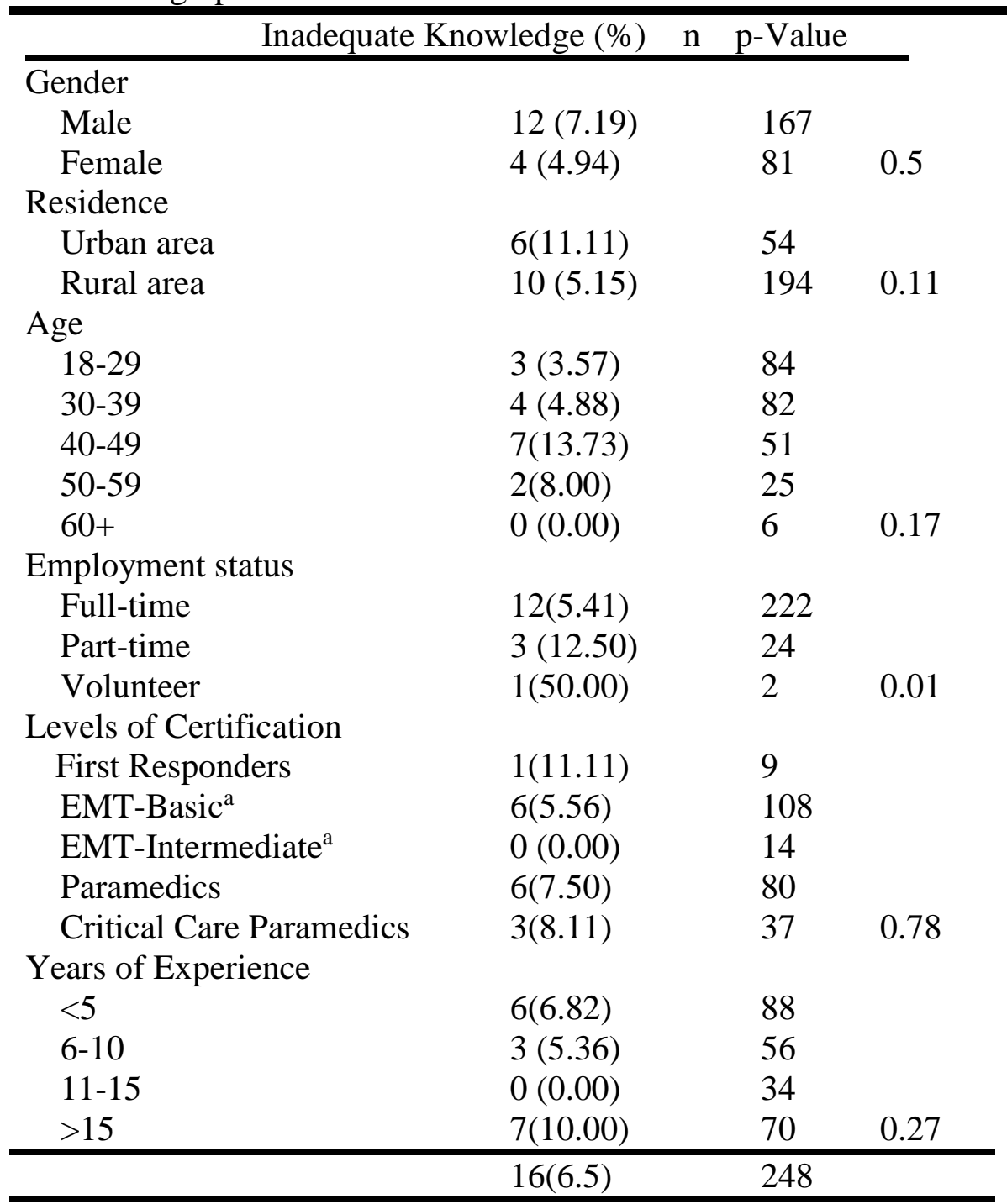

${ }^{\mathrm{a}} \mathrm{EMT}=$ Emergency Medical Technician 
Table 2.7.4: Logistic Regression Modeling of Knowledge of SPs

\begin{tabular}{|c|c|c|c|c|}
\hline \multirow[b]{2}{*}{ Characteristic (Reference) } & \multirow{2}{*}{$\begin{array}{l}\text { Univariate Model } \\
\mathrm{OR}^{\mathrm{a}} \\
\left(\text { Wald } 95 \% \mathrm{CI}^{\mathrm{b}}\right)\end{array}$} & \multicolumn{2}{|c|}{ Multivariate Model (Full) } & \multirow[b]{2}{*}{$\begin{array}{l}\mathrm{p}- \\
\text { value }\end{array}$} \\
\hline & & $\begin{array}{l}\mathrm{p}- \\
\text { value }\end{array}$ & $\begin{array}{l}\mathrm{OR}^{\mathrm{a}} \\
\text { (Wald } 95 \% \mathrm{CI}^{\mathrm{b}} \text { ) }\end{array}$ & \\
\hline \multicolumn{5}{|l|}{ Gender (Male) } \\
\hline Female & $0.67(0.18-1.99)$ & 0.50 & $0.47(0.10-1.73)$ & 0.29 \\
\hline \multicolumn{5}{|l|}{ Residence (Rural area) } \\
\hline Urban area & $2.30(0.75-6.51)$ & 0.12 & $2.41(0.71-7.73)$ & 0.13 \\
\hline \multicolumn{5}{|l|}{ Age(40-49) } \\
\hline $18-29$ & $0.23(0.04-0.88)$ & 0.04 & $0.12(0.01-0.82)$ & 0.03 \\
\hline $30-39$ & $0.32(0.08-1.12)$ & 0.08 & $0.27(0.05-1.19)$ & 0.09 \\
\hline $50+*$ & $0.433(0.06-1.94)$ & 0.31 & $0.30(0.04-1.54)$ & 0.18 \\
\hline \multicolumn{5}{|l|}{ Employment Status (Full-time) } \\
\hline Part-time /Volunteer* & $3.18(0.83-10.05)$ & 0.06 & $7.39(1.51-35.36)$ & 0.01 \\
\hline \multicolumn{5}{|c|}{ Levels of Certification (EMT-Basic/Intermediate*) } \\
\hline First Responder & $2.41(0.12-16.77)$ & 0.43 & $1.77(0.0715 .73)$ & 0.64 \\
\hline Paramedics & $1.56(0.47-5.18)$ & 0.45 & $2.01(0.46-9.20)$ & 0.34 \\
\hline Critical Care Paramedics & $1.70(0.34-6.83)$ & 0.46 & $1.72(0.25-10.36)$ & 0.55 \\
\hline \multicolumn{5}{|l|}{ Years of Experience(>15) } \\
\hline$<5$ & $0.65(0.20-2.07)$ & 0.47 & $1.84(0.26-12.59)$ & 0.53 \\
\hline $6-15^{*}$ & $0.31(0.06-1.16)$ & 0.09 & $0.51(0.08-2.47)$ & 0.42 \\
\hline
\end{tabular}

a. $\mathrm{OR}=$ Odd Ratios

b. $\mathrm{CI}=$ Confidence Interval

* = Merging (50-59 with 60+, part-time with volunteer, EMT-Basic with EMT-Intermediate, and 6-10 with 11-15) 
FIGURE 2.7.1: Stratification of Gender and Residence to Test the Relationship with Knowledge of SPs $(\mathrm{n}=248)$

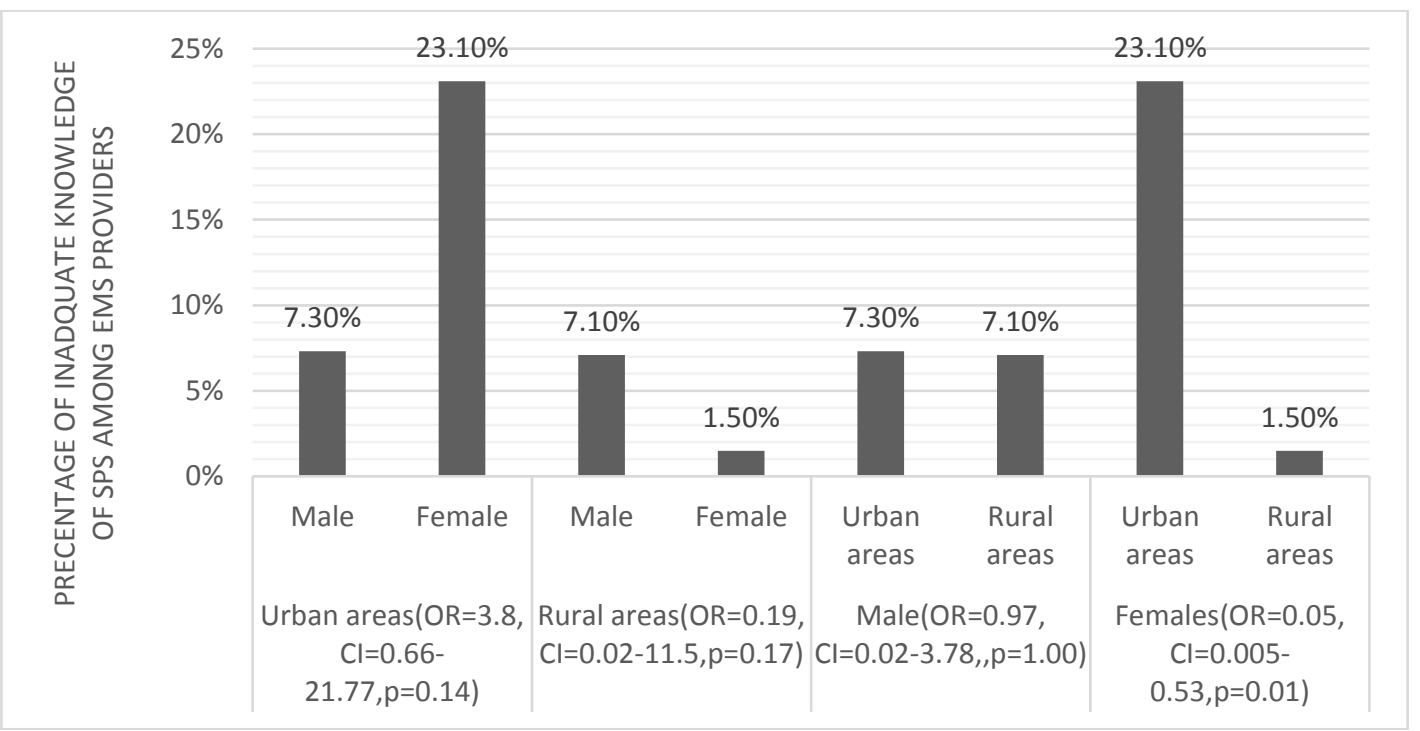

$\mathrm{OR}=$ Odd Ratios

$\mathrm{P}=\mathrm{P}$-value that is calculated by Fisher Test

$\mathrm{CI}=$ confidence interval 
Figure 2.7.2: Attitude Toward the Use of SPs on Every Patient among EMS Providers $(\mathrm{n}=248)$

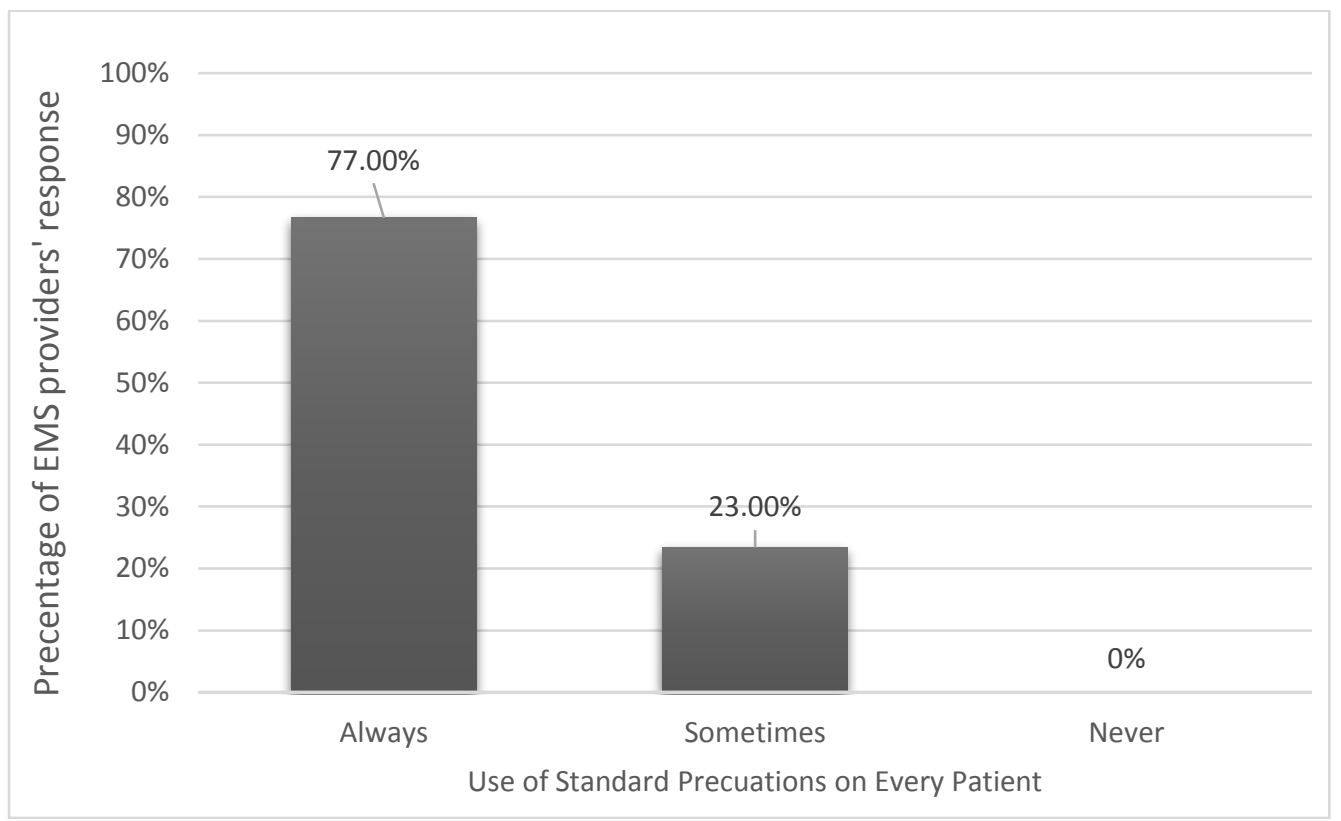


TABLE 2. 7.5: Relationship between Attitudes Toward the Use of SPs and Demographics of EMS Providers

\begin{tabular}{|c|c|c|c|}
\hline & Sometimes (\%) $\mathrm{n}$ & $\mathrm{p}$-Value & \\
\hline \multicolumn{4}{|l|}{ Gender } \\
\hline Male & $44(26.43)$ & 167 & \\
\hline Female & $14(17.23)$ & 81 & 0.11 \\
\hline \multicolumn{4}{|l|}{ Residence } \\
\hline Urban area & 21(38.89) & 54 & \\
\hline Rural area & $37(19.07)$ & 194 & 0.002 \\
\hline \multicolumn{4}{|l|}{ Age } \\
\hline $18-29$ & $13(15.47)$ & 84 & \\
\hline 30-39 & $19(23.17)$ & 82 & \\
\hline $40-49$ & $15(29.41)$ & 51 & \\
\hline $50-59$ & $7(28.00)$ & 25 & \\
\hline $60+$ & $4(66.66)$ & 6 & 0.03 \\
\hline \multicolumn{4}{|l|}{ Employment Status } \\
\hline Full-time & $53(23.87)$ & 222 & \\
\hline Part-time & $5(20.83)$ & 24 & \\
\hline Volunteer & $0(0.00)$ & 2 & .69 \\
\hline \multicolumn{4}{|l|}{ Levels of Certification } \\
\hline First Responders & $1(11.11)$ & 9 & \\
\hline EMT-Basic $^{\mathrm{a}}$ & $21(19.44)$ & 108 & \\
\hline EMT-Intermediate $^{\mathrm{a}}$ & $2(14.28)$ & 14 & \\
\hline Paramedics & $22(27.50)$ & 80 & \\
\hline Critical Care Paramedics & $12(23.43)$ & 37 & 0.31 \\
\hline \multicolumn{4}{|l|}{ Years of Experience } \\
\hline$<5$ & $13(14.77)$ & 88 & \\
\hline $6-10$ & $10(17.85)$ & 56 & \\
\hline $11-15$. & $11(32.35)$ & 34 & \\
\hline \multirow[t]{2}{*}{$>15$} & $24(43.29)$ & 70 & 0.01 \\
\hline & 58 & 248 & \\
\hline
\end{tabular}

${ }^{a}$ EMT $=$ Emergency Medical Technician 
TABLE 2.7.6: Logistic Regression Modeling of Attitudes Toward Standard Precautions

\begin{tabular}{|c|c|c|c|c|}
\hline & \multicolumn{2}{|l|}{ Univariate Model } & \multicolumn{2}{|c|}{ Multivariate Model (Full) } \\
\hline Characteristic (Reference) & $\begin{array}{l}\text { OR }^{\mathrm{a}} \\
\text { (Wald 95\%CI }{ }^{\mathrm{b}} \text { ) }\end{array}$ & $\begin{array}{l}\mathrm{p}- \\
\text { value }\end{array}$ & $\begin{array}{l}\mathrm{OR}^{\mathrm{a}} \\
\text { (Wald 95\% } \mathrm{CI}^{\mathrm{b}} \text { ) }\end{array}$ & $\begin{array}{l}\mathrm{p}- \\
\text { value }\end{array}$ \\
\hline \multicolumn{5}{|l|}{$\overline{\text { Gender (Male) }}$} \\
\hline Female & $0.58(0.29-1.12)$ & 0.11 & $0.74(0.34-1.53)$ & 0.42 \\
\hline \multicolumn{5}{|l|}{ Residence (Urban area) } \\
\hline Rural area & $0.37(0.19-0.71)$ & 0.003 & $0.38(0.18-0.78)$ & 0.008 \\
\hline \multicolumn{5}{|l|}{ Age (18-29) } \\
\hline $30-39$ & $1.65(0.76-3.67)$ & 0.21 & $0.87(0.32-2.34)$ & 0.79 \\
\hline $40-49$ & $2.27(0.98-5.36)$ & 0.06 & $1.06(0.31-3.35)$ & 0.92 \\
\hline $50-59$ & $2.12(0.71-6.01)$ & 0.16 & $0.92(0.22-3.54)$ & 0.91 \\
\hline $60+$ & $\begin{array}{l}10.91(1.93- \\
84.93)\end{array}$ & 0.009 & $3.64(0.48-34.43)$ & 0.21 \\
\hline \multicolumn{5}{|l|}{ Employment status (Full-time) } \\
\hline Part-time/Volunteer* & $0.75(0.24-1.97)$ & 0.59 & $0.96(0.27-2.83)$ & 0.94 \\
\hline \multicolumn{5}{|c|}{ Levels of Certification (EMT-Basic ${ }^{\mathrm{a}}$ ) } \\
\hline First Responder & $0.51(0.02-3.05)$ & 0.54 & $0.64(0.03-4.05)$ & 0.69 \\
\hline EMT-Intermediate ${ }^{\mathrm{a}}$ & $0.69(0.10-2.79)$ & 0.82 & $0.85(0.12-3.76)$ & 0.85 \\
\hline Paramedics & $1.57(0.79-3.13)$ & 0.31 & $0.88(0.38-2.03)$ & 0.78 \\
\hline Critical Care Paramedics & $1.98(0.84-4.56)$ & 0.22 & $0.95(0.32-2.67)$ & 0.92 \\
\hline \multicolumn{5}{|l|}{ Years of Experience $(<5)$} \\
\hline $6-10$ & $1.25(0.49-3.08)$ & 0.62 & $1.17(0.42-3.16)$ & 0.74 \\
\hline $11-15$ & $2.76(1.07-7.02)$ & 0.03 & $2.44(0.71-8.56)$ & 0.15 \\
\hline$>15$ & $3.01(1.42-6.65)$ & 0.004 & $2.68(0.77-9.97)$ & 0.12 \\
\hline
\end{tabular}

a. $\mathrm{OR}=$ Odd ratios.

b. $\mathrm{CI}=$ Confidence interval.

$*=$ Merging (part-time with volunteer) 
FIGURE 2.7.3: Stratification Gender and Residence to Test the Relationship with Attitude Toward SPs $(n=248)$

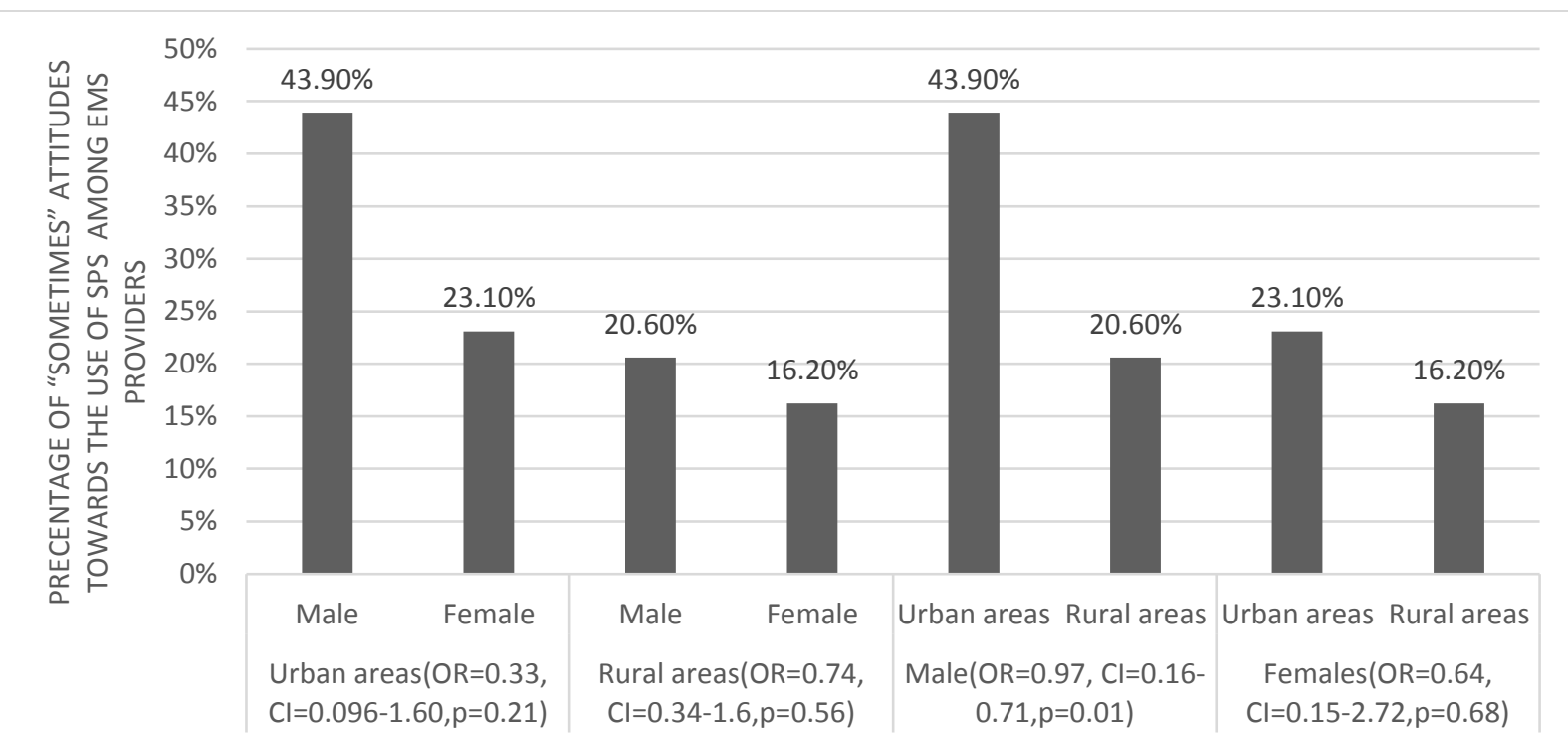

OR $=$ Odd Ratios

$\mathrm{p}=\mathrm{p}$--value that is calculated by Fisher Test

$\mathrm{CI}=$ Confidence Interval 
Table 2.7.7: Reasons to Not Use SPs on Every Patient among EMS Providers

\begin{tabular}{llll}
\hline & Urban Areas (\%) & Rural Areas (\%) & $\mathrm{n}(\%)$ \\
\hline I don't know what SPs are & $0(0.00)$ & $1(3.00)$ & $1(1.92)$ \\
I don't have time to use SPs on every patient & $10(52.63)$ & $10(30.30)$ & $20(38.46)$ \\
I have immunity against infections & $0(0.00)$ & $0(0.00)$ & $0(0.00)$ \\
I only use SPs on really bad calls & $9(47.36)$ & $22(66.67)$ & $31(59.62)$ \\
\hline & $19(36.53)$ & $33(63.43)$ & 52
\end{tabular}


TABLE 2.7. 8: Practice of SPs

Measures to be Taken to Avoid Contact to Blood and Body Fluids

n $(\%)$

1. Wear gloves, wash hand regularly, avoid recapping needles, and dispose of sharps in appropriate sharps

container

2. Wear gloves, wash hand regularly, avoid recapping needles, dispose of sharps in appropriate sharps container, $120(48.4)$ and cover open wounds

3. Wear gloves, wash hand regularly, avoid recapping 74(30.0) needles, dispose of sharps in appropriate sharps container, wear mask, eye protection, and cover open wounds 4. Wear gloves, wash hand regularly, dispose of sharps in appropriate sharps container, and avoid treating open wounds 
TABLE 2.7. 9: Relationship between Practice of SPs and Demographics of the EMS Providers

\begin{tabular}{|c|c|c|c|}
\hline & $\begin{array}{l}\text { Suboptimal } \\
\text { Practice (\%) }\end{array}$ & $\mathrm{n}$ & p-value \\
\hline \multicolumn{4}{|l|}{ Gender } \\
\hline Male & $121(72.5)$ & 167 & \\
\hline Female & $53(65.43)$ & 81 & 0.25 \\
\hline \multicolumn{4}{|l|}{ Residence } \\
\hline Urban area & $39(72.22)$ & 54 & \\
\hline Rural area & $135(69.5)$ & 194 & 0.70 \\
\hline \multicolumn{4}{|l|}{ Age } \\
\hline $18-29$ & $60(71.43)$ & 84 & \\
\hline $30-39$ & $58(70.73)$ & 82 & \\
\hline $40-49$ & $33(64.70)$ & 51 & \\
\hline $50-59$ & $19(76.00)$ & 25 & \\
\hline $60+$ & $4(66.66)$ & 6 & 0.87 \\
\hline \multicolumn{4}{|l|}{ Employment status } \\
\hline Full-time & $156(70.27)$ & 222 & \\
\hline Part-time & $17(70.83)$ & 24 & \\
\hline Volunteer & $1(50.00)$ & 2 & 0.82 \\
\hline \multicolumn{4}{|l|}{ Levels of Certification } \\
\hline First Responders & $4(44.44)$ & 9 & \\
\hline EMT-Basic $^{\mathrm{a}}$ & $78(72.22)$ & 108 & \\
\hline EMT-Intermediate $^{\mathrm{a}}$ & $9(64.29)$ & 14 & \\
\hline Paramedics & $58(72.50)$ & 80 & \\
\hline Critical Care Paramedics & $25(67.57)$ & 37 & 0.45 \\
\hline \multicolumn{4}{|l|}{ Years of Experience } \\
\hline$<5$ & $57(64.77)$ & 88 & \\
\hline $6-10$ & $39(69.64)$ & 56 & \\
\hline $11-15$ & $27(79.41)$ & 34 & \\
\hline \multirow[t]{2}{*}{$>15$} & $51(72.86)$ & 70 & 0.41 \\
\hline & 58 & 248 & \\
\hline
\end{tabular}

${ }^{\mathrm{a} E M T}=$ Emergency Medical Technician 
TABLE 2.7.10: Logistic Regression Modeling of Attitude of SPs

\begin{tabular}{|c|c|c|c|c|}
\hline \multicolumn{3}{|c|}{ Univariate Model } & \multicolumn{2}{|c|}{ Multivariate Model (Full) } \\
\hline Characteristic (Reference) & $\begin{array}{l}\mathrm{OR}^{\mathrm{a}} \\
\left(\mathrm{W} \text { ald } 95 \% \mathrm{CI}^{\mathrm{b}}\right)\end{array}$ & $\begin{array}{l}\mathrm{p} \text { - } \\
\text { value }\end{array}$ & $\begin{array}{l}\mathrm{OR}^{\mathrm{a}} \\
\left(\mathrm{W} \text { ald } 95 \% \mathrm{CI}^{\mathrm{b}}\right)\end{array}$ & $\begin{array}{l}\mathrm{p}- \\
\text { value }\end{array}$ \\
\hline \multicolumn{5}{|l|}{ Gender (Male) } \\
\hline Female & $0.72(0.40-1.28)$ & 0.25 & $0.76(0.41-1.44)$ & 0.40 \\
\hline \multicolumn{5}{|l|}{ Residence (Urban area) } \\
\hline Rural area & $0.88(0.44-1.69)$ & 0.70 & $0.87(0.42-1.76)$ & 0.70 \\
\hline \multicolumn{5}{|l|}{ Age(18-29) } \\
\hline $30-39$ & $0.96(0.49-1.89)$ & 0.92 & $0.59(0.26-1.33)$ & 0.20 \\
\hline $40-49$ & $0.73(0.34-1.55)$ & 0.41 & $0.37(0.14-0.99)$ & 0.06 \\
\hline $50-59$ & $1.26(0.47-3.82)$ & 0.65 & $0.58(0.17-2.16)$ & 0.40 \\
\hline $60+$ & $0.80(0.14-6.04)$ & 0.80 & $0.298(0.04-2.62)$ & 0.22 \\
\hline \multicolumn{5}{|c|}{ Employment Status (Full-time) } \\
\hline Part-time & $1.02(0.422-2.76)$ & 0.96 & $0.99(0.37-2.84)$ & 0.98 \\
\hline Volunteer & $0.42(0.01-10.79)$ & 0.54 & $1.58(0.05-47.28)$ & 0.76 \\
\hline \multicolumn{5}{|c|}{ Levels of Certification (EMT-Basic ${ }^{a}$ ) } \\
\hline First Responders & $0.30(0.07-1.23)$ & 0.09 & $0.34(0.07-1.53)$ & 0.15 \\
\hline EMT-Intermediate $^{\mathrm{a}}$ & $0.69(0.22-2.40)$ & 0.53 & $0.70(0.21-2.57)$ & 0.54 \\
\hline Paramedics & $1.01(0.53-1.95)$ & 0.96 & $0.68(0.32-1.46)$ & 0.33 \\
\hline Critical Care Paramedics & $0.80(0.36-1.83)$ & 0.59 & $0.54(0.20-1.46)$ & 0.22 \\
\hline \multicolumn{5}{|l|}{ Years of Experience $(<5)$} \\
\hline $6-10$ & $1.24(0.61-2.59)$ & 0.54 & $1.48(0.66-3.41)$ & 0.33 \\
\hline $11-15$ & $2.09(0.85-5.72)$ & 0.12 & $3.50(1.127-11.85)$ & 0.03 \\
\hline$>15$ & $1.46(0.74-2.92)$ & 0.27 & $3.12(1.044-9.62)$ & 0.04 \\
\hline
\end{tabular}

a. $\mathrm{OR}=$ Odd Ratios

b. $\mathrm{CI}=$ Confidence Interval 
FIGURE 2.7.4: Stratification of Gender and Residence to Test the Relationship with Practice of SPs (n=248)

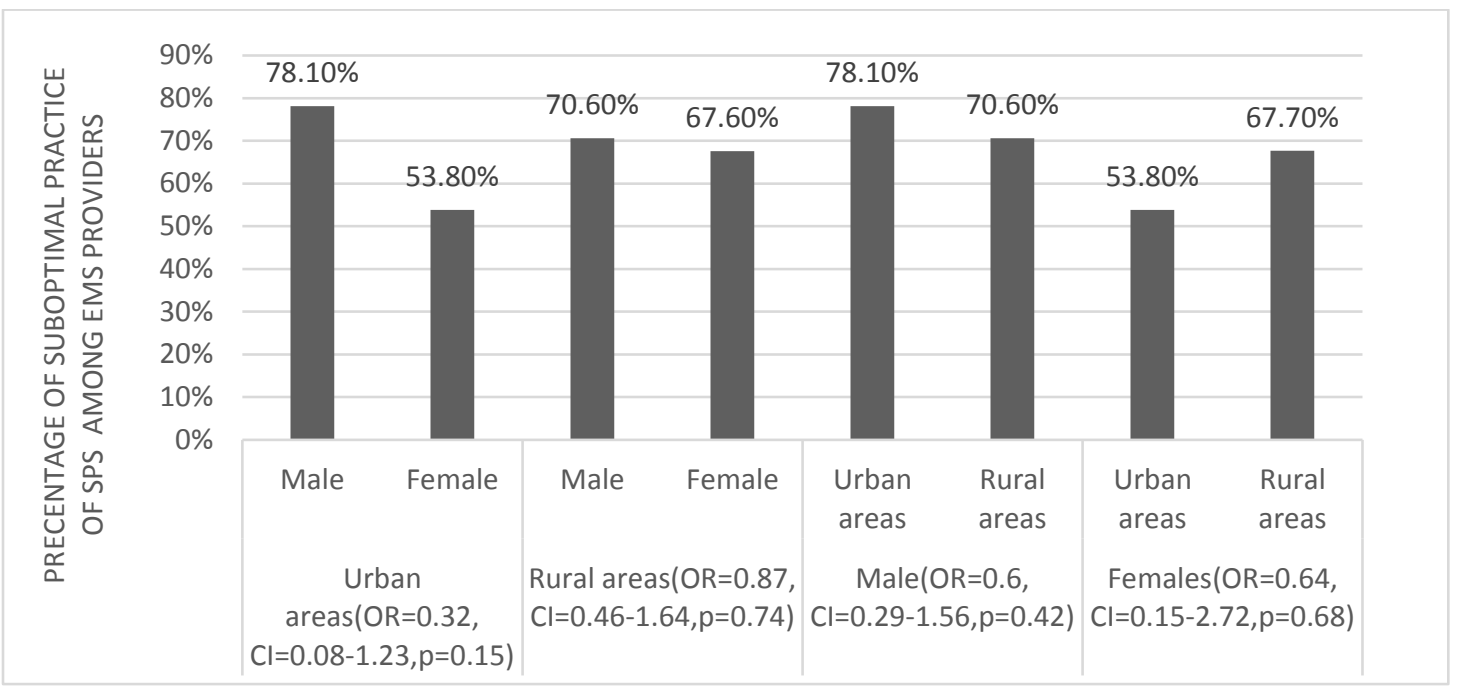

$\mathrm{OR}=$ Odd Ratios

$\mathrm{p}=\mathrm{p}$-value that is calculated by Fisher Test

$\mathrm{CI}=$ Confidence Interval 
TABLE 2.7.11: Barriers to the Use of SPs

\begin{tabular}{llll}
\hline Barriers & $\begin{array}{l}\text { Urban } \\
\text { Areas } \\
(\mathbf{\%})\end{array}$ & $\begin{array}{l}\text { Rural } \\
\text { Areas } \\
(\%)\end{array}$ & n (\%) \\
\hline 1. Inadequate supply of gloves & $5(20.00)$ & $13(14.13)$ & $18(15.38)$ \\
2. No hand sanitizer in the ambulance & $4(16.00)$ & $8(8.70)$ & $12(10.26)$ \\
3. Inadequate supply of sharps containers & $4(16.00)$ & $8(8.70)$ & $12(10.26)$ \\
4. Inadequate supply of mask and eyes protection & $9(36.00)$ & $30(32.61)$ & $39(33.33)$ \\
5. Difficulty in receiving restocking supplies & $3(12.00)$ & $33(35.86)$ & $36(30.77)$ \\
\hline
\end{tabular}




\section{CHAPTER 3: Needlestick Injuries among Emergency Medical Services Providers in Urban and Rural}

Areas

\section{INTRODUCTION}

Occupational injury and illness occur across an extensive variety of occupations. An estimated 320,471 employees die annually from work-related transmittable infectious diseases worldwide [1]. Compared to many other types of occupations, Health Care Workers (HCWs) are at a greater risk of harm from exposure to blood and other pathogens. A study reveals a high level of occupational exposure to blood among HCWs [2)]. Emergency Medical Services (EMS) providers are often exposed to blood, resulting in concerns regarding transmission of blood-borne pathogens [3, 4]. This places EMS providers at higher risk of occupational exposure to infectious diseases.

Due to many Needlestick Injuries (NSIs) and the improper use of sharp devices, the Needlestick Safety and Prevention Act was created in 2000 to increase protections of HCWs from exposure to blood-borne pathogens [5]. However, NSIs are the most common occupational injuries among EMS providers worldwide [6, 7]. NSIs rate among EMS providers is higher than most hospital-based HCWs in United States [8, 9]. A study found that $80 \%$ of NSIs occurred without using proper safety devices [10]. Safety-engineered needles and sharps devices that are structurally developed are designed to reduce the risk of NSIs to HCWs including EMS providers [9]. Accordingly, training of how to use safety devices along with sufficient provision by the company contribute to decrease the rate of NSIs and other routes of blood exposure among EMS providers [10]. A study shows that there is a relative decease of NSIs among EMS providers due to the implantation of needlestick prevention polices, including self-capping needle devices and an annual review of all NSIs [4].

The risk of transmission of bloodborne pathogens can result in contracting infectious diseases. The most common bloodborne pathogens, which HCWs are often exposed to through percutaneous injuries including NSIs and sharps injuries or blood and body fluids exposure, are the human immunodeficiency virus (HIV), 
hepatitis B virus (HBV), and hepatitis C virus (HCV)[11]. Descriptive studies indicate an increase of acute HBV infection during 2006-2013 [12] and acute HCV infection from 2006 to 2012 among persons aged $\leq 30$ years in rural areas [13]. These findings show that there was an increase in the level of NSIs among HCWs in rural areas, and therefore there is an urgent need for intervention [14].

EMS providers face increased levels of fatigue, reduced sleep, and encountered violence in rural areas $[15,16] .55 \%$ of EMS providers in the United States suffer from fatigue, which is higher than approximately $40 \%$ of white-collar workers who also complain of fatigue [17]. Accordingly, poor sleep and fatigue adversely affect safety outcomes of EMS providers [18]. In addition, a pervious study shows that gender is associated with occupational exposure to blood, where male EMS providers are often more exposed to non-intact skin than female EMS providers [8]. Unfortunately, there is not enough information regarding percutaneous injuries, including NSIs and other sharp injuries among male and female EMS providers specifically in rural areas. The objective of this study was to assess the knowledge of EMS providers regarding NSIs and to examine differences by demographics.

\section{METHODS}

\subsection{Study Design and Population}

This project was part of a cross-sectional survey conducted with a simple random sample of certified EMS providers in West Virginia regarding the knowledge, consistency, and practice of standard precaution among EMS Providers. An invitation email was sent to randomly selected EMS agencies from a comprehensive list of providers from the Office of West Virginia Emergency Medical Services. Six out of twelve different agencies replied and agreed to participate in distributing the survey link to their membership. The entire pool of certified EMS providers of these agencies totaled 522 EMS providers, varying from critical care paramedics, paramedics, EMT-advanced, EMT-basic, and emergency medical responders. Study instructions and an 
electronic cover letter were shown at the beginning of the survey. This study was approved by the West Virginia University Institutional Review Board.

\subsection{Survey Instrument}

This project consists of three sections: socio-demographic characteristics, NSIs, and needle stick training. The first section collected demographics, including age (18-29 years, 30-39 years, 40-49 years, 50-59 years and 60+ years), gender (male and female), and place of residence, defined as urban or rural according to standards used by the US Census Bureau as reported by the United States Office of Management and Budget $(\mathrm{OMB})(19)$. Urban areas were defined as having a population of over 50,000. Rural areas were defined as having a population of less than 50,000. Additional demographics included level of certification (First Responders, EMT-Basic, EMT-Intermediate, Paramedics and Critical Care Paramedics), employment status (full-time, part-time and volunteer) and years of service ( $<5$ years, 6-10 years, 11-15 years, and $>15$ years).

The second section asked about whether or not EMS providers had needle stick prevention training before (yes/no).

The third section was focused on NSIs. EMS providers were asked about whether or not had gotten NSIs in the past twelve months (the year of 2016) (yes/no).

\subsection{Survey Data Collection}

The web based survey was administered using the secure, online software Qualtrics (20) via email from EMS agency directors in West Virginia. Certified EMS providers who were currently working in West Virginia and over eighteen years old were included and eligible to complete the anonymous online survey. The web link to the online survey was active for 30 days from the time of sending out an email to EMS directors, and two reminder emails were sent. The EMS provider received the email and opened the hyperlink, which automatically took them to the website. At the beginning of the online survey, a general description of the study 
and the cover letter were provided to each respondent. After participants elected to take the survey, survey questions became available.

\subsection{Data Analysis}

Data analysis was performed using Statistical Analysis System (SAS) software, Version 9.4. Descriptive statistics were performed first to summarize EMS providers' demographic characteristics, including summary tables, box-plots, frequencies, and proportions. Then, a chi-square test was used to compare categorical variables. All findings are reported using 95\% confidence intervals (CIs). Furthermore, a logistic regression (adjusted model) was used to explain the relationship between independents and outcome. Odds ratios (ORs) and $95 \%$ confidence intervals (CIs) were estimated. Differences at the $\alpha=0.05$ level were considered statistically significant.

\section{RESULTS}

\subsection{Description of the Study Participant}

A total of 247 of $522(47.31 \%)$ EMS providers completed the survey. 166 (67.21\%) were male, and 81 $(32.79 \%)$ were female. The majority of the EMS providers $(194,78.54 \%)$ reported working in a rural area, with $53(21.46 \%)$ serving in urban areas. The majority of EMS providers were full-time $(221,89.47 \%)$; however, part-time and volunteer totaled $24(9.72 \%)$ and $2(0.81 \%)$, respectively. Most EMS providers were between the ages of 18 and $29(84,33.9 \%)$ and then between 30 and $39(82,33.20 \%)$, followed by 60 and above $(6,2.43 \%)$. A majority of EMS providers' certifications were EMT-Basic (107, 43.32\%), followed by paramedics (80, 32.39\%), while only 9 (3.64\%) were first responders. 87 (35.22\%) of EMS providers reported having less than 5 years of experience in EMS, followed by more than 15 years $(70,28.43 \%)$. EMS providers who had needlestick prevention training totaled $209(84.62 \%)$, while $38(15.38 \%)$ did not have any previous needlestick prevention training (Table 1). 


\subsection{Needlestick Injuries and EMS Providers}

EMS providers reported of whether the EMS providers had NSIs past twelve months (the year of 2016). The majority of EMS providers $(81.99 \%, \mathrm{n}=202)$ reported no NSI ever and $18.21 \%(\mathrm{n}=45)$ had at least one NSI within past twelve months (Table1).

Chi-square tests were used to evaluate the relationship between NSIs and demographics of the EMS providers (Table 2). There was a statistically significant association between age and NSIs $(\mathrm{p}=0.001)$. EMS providers at age 60 years and older $(50.00 \%)$ was the highest proportion among age group, followed by ages 50-59 (40.00\%) and 40-49 (19.29\%). Level of certification was statistically associated with NSIs ( $\mathrm{p}=0.0005)$.

Critical Care Paramedics (32.43\%) were the highest proportion of NSIs compared to paramedics (27.50\%) and EMT-Intermediate (21.43\%), respectively. Also, years of experience was statistically associated with NSIs $(\mathrm{p}=<.0001)$. EMS providers with more than 15 years of experience $(38.57 \%)$ were the highest proportion of participants who received NSIs, followed by those with 11-15 years of experience (14.71\%). In contrast, gender, residence, needle stick training, and employment status were not significantly associated with NSIs.

Stratification methods were performed to evaluate the relationship between residence and gender regarding NSIs. The figure shows gender and NSIs among stratified residence (urban and rural areas). There is quite a varying proportion in NSIs between males (22.50\%) and females (38.50\%) in urban areas, with no statistically significant differences $(\mathrm{OR}=2.15, \mathrm{CI}=0.56-8.23, \mathrm{p}=0.29)$. Likewise, there was no statistically significant relationship between gender and NSIs in rural areas $(\mathrm{OR}=0.86, \mathrm{CI}=0.38-1.95, \mathrm{p}=0.83)$. Figure 2 also shows residence with NSIs among stratified gender. There was high varying proportion in NSIs between urban areas $(38.50 \%)$ and rural areas $(14.70 \%)$ among females $(\mathrm{OR}=0.28, \mathrm{CI}=0.075-1.02, \mathrm{p}=0.05)$.

Table 3 demonstrates an adjusted logistic regression for other variables. There were no variables shown significant association with NSIs, controlling the covariates. 


\section{DISCUSSION}

The Centers for Disease Control and Prevention (CDC) and the United States Occupational Safety and Health Administration (OSHA) created prevention of bloodborne pathogen exposure and needlestick safety guidelines to protect HCWs, including EMS providers, from contracting infectious diseases [21, 22]. Although these efforts have resulted in well-grounded and defined regulations, EMS providers frequently are at risk of occupational injuries and illnesses [3, 4]. A probable and significant concern of such injuries that cause infectious diseases are NSIs [6, 7]. NSIs are the second-most route of exposure to blood after non-intact skin among EMS providers [23]. This study assessed the knowledge of EMS providers regarding NSIs and examined differences by demographics. In this study, 247 of 522 (47.5 \%) targeted EMS providers completed a crosssectional survey. The majority of EMS providers $(81.99 \%, \mathrm{n}=202)$ reported no NSI ever and $18.21 \%(\mathrm{n}=45)$ had at least one NSI within past twelve months (Table1). This low proportion of NSIs among EMS providers is likely due to consistent compliance with standard precautions. Otherwise, they underestimated the risk of the NSIs, so they did not report them as significant to occupational injuries resulting in harmful diseases. A previous study observed that EMS providers only report NSIs when they seem at risk of transmission [24]. More specifically, EMS providers are most likely to report deep or moderate NSIs than those that are superficial [24].

In this study, we found that age and years of experience of EMS providers were associated with NSIs.

Older and the more experienced EMS providers had more NSIs. They were most likely to underestimate the risk of NSIs, leading to the transmission of infectious diseases. Consequently, they inconsistently used standard precautions and became less self-protective over time. In contrast to a previous study, age and years of experience of EMS providers did not show any relationship with occupational exposures to blood in general [8]. In addition, they did not report the incidents as occupational injures [24]. We also found a relationship between levels of certification and NSIs, where the more certified EMS providers had more NSIs. Varied positions in the EMS system have differing levels of certifications and different job descriptions. Paramedics, who provide 
advanced emergency care to patients, may receive more exposure to blood than Emergency Medical

Technicians (EMTs), who provide basic emergency care [25]. Future research should investigate the cause of an increased rate of NSIs among experienced, old, and high-certified EMS providers.

EMS providers confront increased numbers of agitated patients, less sleep, and increased levels of tiredness in rural areas, which can have a negative impact on their safety performance $[15,16,18]$. In our study, urban EMS providers (26\%) had slightly higher proportion of NSIs then rural EMS providers (16\%), but this small difference does not show any relationship between residence and NSIs, nor between both areas. Furthermore, our findings generally showed no association between gender and NSIs, where no difference in proportion of NSIs was found between male and female EMS providers. However, Boal et al found males are more often exposed to blood than females [8], although females considerably tended to report more occupational exposures than males [24]. Accordingly, when stratifying gender and residence based on NSIs, we found quite small varying of NSI occurrence between male and female in urban areas, where females had more NSIs than males. Also, this result is in contrast to Boal et al's study, where males were often exposed to more blood than females, regardless of the place of residence [25]. On the other hand, there was large varying of NSI occurrence between urban areas (38.50\%) and rural areas (14.70\%) among females. This result indicates females are more prone to exposure to NSIs, specifically in urban areas. The results indicate a need to further examine NSIs and provide information regarding the safety precautions among urban and rural EMS providers. The results will help identify areas of possible improvement and show how to implement an effective program to prevent NSIs and other routes of exposure to blood in urban and rural areas.

This study has some limitations. The response rate of $47.31 \%$ created the potential for nonresponse bias, resulting in non-generalizable outcomes. For example, EMS providers who did not have NSIs tended to respond, and others who had NSIs may have been non-responsive to the survey. In addition, responders might have had recall bias because they might recall events that have occurred at one time, when they occurred at another time. Additionally, these results cannot necessarily be generalized directly to other EMS systems, as the 
study was limited to one state (West Virginia), and the results may not be applicable to other states. Finally, there was no way of categorizing all EMS agencies responded as urban or rural because some agencies include stations and squads in different locations.

\section{CONCLUSION}

A survey of NSIs among EMS providers indicates age and years of experience of EMS providers are associated with NSIs. Older, more experienced, and persons with a higher certification level report more NSIs in the previous 12 months. Future research should investigate the cause of an increased rate of NSIs among experienced, old, and high-certified EMS providers. The survey also indicates female EMS providers are more prone to exposure to blood through NSIs specifically in urban areas, but there is no indication of gender difference in rural areas regrading increased NSIs. The results indicate a need to further examine NSIs and provide information regarding the safety precautions among urban and rural EMS providers.

Summary (overall conclusion):

In prehospital setting, female EMS providers are more exposed to blood and bodily fluids than men in urban areas and are less knowledgeable of SPs. In addition, Older, more experienced, and persons with a higher certification level report more NSIs and are inconsistent compliance with SPs. On the other hand. Exposure to blood borne pathogens largely occur among nurses and physicians through percutaneous injuries caused mainly by needlestick in morning shift in a hospital-based setting. As I had meetings with my EMS directors and infectious officers while conducting my dissertation, under- reporting among both EMS providers and hospitalbased HWCS is a big concern. Future study should assess a blood borne pathogens program and role of mangers to enhance occupational health and safety among their employees. 


\section{REFERENCES}

1. Hämäläinen, P., Takala, J., \& Saarela, K. L. (2007). Global estimates of fatal work-related diseases. American Journal of Industrial Medicine, 50(1): 28-41.

2. Liu, X. N., Sun, X. Y., van Genugten, L., Shi, Y. H., Wang, Y. L., Niu, W. Y., \& Richardus, J. H. (2014) Occupational exposure to blood and compliance with standard precautions among health care workers in Beijing, China. American Journal of Infection Control.,42(3): e37-e38.

3. Heick, R., Young, T., \& Peek-Asa, C. (2009) Occupational injuries among emergency medical service providers in the United States. Journal of Occupational and Environmental Medicine. , 51(8): 963-968.

4. Sayed, M. E., Kue, R., McNeil, C., \& Dyer, K. S. A. (2011). Descriptive analysis of occupational health exposures in an urban emergency medical services system: 2007-2009. Prehospital Emergency Care, 15(4): 506-510.

5. Jagger, J., Perry, J., Gomaa, A., \& Phillips, E. K. (2008). The impact of U.S. policies to protect Healthcare workers from bloodborne pathogens: The critical role of safety engineered devices. Journal of Infection and Public Health. , 1(2): 62-71.

6. Garus-Pakowska, A., Szatko, F., \& Ulrichs, M. (2017). Work-Related Accidents and Sharp Injuries in Paramedics - Illustrated with an Example of a Multi-Specialist Hospital, Located in Central Poland. International Journal of Environmental Research and Public Health,14(8): 901. 
7. Yilmaz, A., Serinken, M., Dal, O., Yaylac1, S., \& Karcioglu, O. (2016). Work-related injuries among emergency medical technicians in western Turkey. Prehospital and Disaster Medicine, 31(5): 505-508.

8. Boal, W., Leiss, J., Ratcliffe, J., Sousa, S., Lyden, J., Li, J., \& Jagger, J. (2010). The National Study to Prevent Blood Exposure in Paramedics: Rates of Exposure to Blood. International Archives of Occupational and Environmental Health, 83(2): 191-199.

9. Chen, G. X., \& Jenkins, E. L.( 2007). Potential work-related exposures to blood borne pathogens by industry and occupation in the United States part II: A telephone interview study. American Journal of Industrial Medicine, 50: 285-292.

10. Leiss, J. K., Sousa, S., \& Boal, W. L. (2009). Circumstances surrounding occupational blood exposure events in the National Study to Prevent Blood Exposure in Paramedics. Industrial Health, 47(2): 139-44.

11. Centers for Disease Control and Prevention (CDC).( 2010). STOP STICKS CAMPAIGN. The National Institute for Occupational Safety and Health (NIOSH). Last updated: September 28, 2010. Retrieved from https://www.cdc.gov/niosh/stopsticks/bloodborne.html\#HIV. Accessed October 7, 2017.

12. Harris, A. M., Iqbal, K., Schillie, S., Britton, J., Kainer, M., Tressler, S., \& Vellozzi, C. (2016). Increases in Acute Hepatitis B Virus Infections-Kentucky, Tennessee, and West Virginia, 2006-2013. $C D C$, 65(3): 47-50. Retrieved from https://www.cdc.gov/mmwr/volumes/65/wr/mm6503a2.htm.

13. Zibbell, J., Iqbal, K., Patel, R. and et al.( 2015). Increases in hepatitis $C$ virus infection related to injection drug use among persons aged $\leq 30$ years-Kentucky, Tennessee, Virginia, and West Virginia, 2006-2012. CDC,64(17): 453-458. Retrieved from https://www.cdc.gov/mmwr/preview/mmwrhtml/mm6417a2.htm.

14. Ngatu, N. R., Phillips, E. K., Wembonyama, O. S., Hirota, R., Kaunge, N. J., Mbutshu, L. H., \& Suganuma, N. (2012). Practice of universal precautions and risk of occupational blood-borne viral infection among Congolese health care workers. American Journal of Infection Control,40(1): 68.

15. Pyper, Z., \& Paterson, J. L.( 2016). Fatigue and mental health in Australian rural and regional ambulance personnel. Emergency Medicine Australasia, 28(1): 62-66.

16. Gormley, M. A., Crowe, R. P., Bentley, M. A., \& Levine, R. A.( 2016). National description of violence toward emergency medical services personnel. Prehospital Emergency Care, 20(4): 439-47.

17. Patterson, P. D., Suffoletto, B. P., Kupas, D. F., Weaver, M. D., \& Hostler, D.( 2010) Sleep quality and fatigue among prehospital providers. Prehospital Emergency. Care, 14(2): 187-193.

18. Patterson, P. D., Weaver, M. D., Frank, R. C., et al. (2012). Association between poor sleep, fatigue, and safety outcomes in emergency medical services providers. Prehospital Emergency Care.16 (1): 8697.

19. United States Census Bureau. Urban and Rural. Retrieved from https://www.census.gov/geo/reference/urban-rural.html. Accessed October 7, 2017.

20. Qualtrics. About Qualtrics. (2010). Retrieved from http://www.qualtrics.com/about-qualtrics/.

21. Centers for Disease Control and Prevention.( 1987).Recommendation for prevention of HIV Transmission in Health-care settings. Morbidity and Mortality Weekly Report,36(2): 1-18. Retrieved from https://www.cdc.gov/mmwr/preview/mmwrhtml/00023587.htm.

22. Jagger, J., Perry, J., Gomaa, A., \& Phillips, E. K.( 2008).The impact of U.S. policies to protect healthcare workers from bloodborne pathogens: The critical role of safety engineered devices. Journal of Infection and Public Health, 1(2): 62-71.

23. Leiss, J. K., Ratcliffe, J. M., Lyden, J. T., Sousa, S., Orelien, J. G., Boal, W. L., \& Jagger, J.( 2006). Blood exposure among paramedics: Incidence rates from the national study to prevent blood exposure in paramedics. Ann Epidemiol,16: 720-725.

24. Boal, W. L., Leiss, J. K., Sousa, S., Lyden, J. T., Li, J., \& Jagger. J.( 2008) The national study to prevent blood exposure in paramedics: exposure reporting. American Journal of Industrial Medicine,51(3): 21322 . 
25. Harris, S. A., \& Nicolai, L. A. (2010).Occupational exposures in emergency medical service providers and knowledge of and compliance with universal precautions. AJIC: American Journal of Infection Control, 38(2): 86-94.

\section{TABLES and FIGURES}

\section{TABLE3. 7.1: Demographics of EMS Providers}

$$
(\mathrm{n}=247)
$$

Variables

n $(\%)$

Needlestick Injuries

Yes

$45(18.21)$

No

Residence

Urban areas

202(81.78)

Rural areas

53 (21.46)

194 (78.54)

Needlestick Training

Yes

$209(84.62)$

No

38 (15.38)

Gender

Male

$166(67.21)$

Female

81 (32.79) 
Age

18-29

30-39

40-49

50-59

$60+$

Employment status

Full-time

Part-time

Volunteer

Levels of Certification

First Responders (Emergency

Medical )

EMT-Basics $^{\text {a }}$

EMT-Intermediate $^{\mathrm{a}}$

Paramedics

Critical Care Paramedics

Years of Experience

$<5$

6-10

11-15

$>15$
$83(33.60)$

$82(33.20)$

$51(20.65)$

$25(10.12)$

$06(2.43)$

$221(89.47)$

$24(9.72)$

$2(0.81)$

$9(3.64)$

$107(43.32)$

14 (5.67)

80 (32.39)

37 (14.98)

87 (35.22)

56 (22.67)

34 (13.77)

$70(28.34)$

${ }^{\mathrm{a} E M T}=$ Emergency Medical Technician

TABLE 3.7.2: Demographics of EMS Providers Reporting a NSI in Last 12 months $(\mathrm{n}=247)$

\begin{tabular}{llll}
\hline & $\begin{array}{l}\text { Reported } \\
\text { NSI (\%) }\end{array}$ & n & p-Value* \\
\hline Gender & $30(18.07)$ & 166 & \\
$\quad$ Male & $15(18.52)$ & 81 & 0.93 \\
$\quad$ Female & & \\
Residence & $14(26.42)$ & 53 & \\
$\quad$ Urban areas & $31(15.98)$ & 194 & 0.08 \\
$\quad$ Rural areas & & & \\
Needlestick Training & $41(19.62)$ & 209 & \\
Yes & $4(10.53)$ & 38 & 0.18 \\
No & & & \\
Age & $7(8.43)$ & 83 & \\
18-29 & $15(18.29)$ & 82 & \\
$30-39$ & $10(19.60)$ & 51 & \\
$40-49$ & $10(40.00)$ & 25 & \\
$50-59$ & & 52 & \\
& &
\end{tabular}




\begin{tabular}{llll}
$60+$ & $3(50.00)$ & 6 & 0.001 \\
Employment status & & & \\
$\quad$ Full-time & $43(19.46)$ & 221 & \\
Part-time & $2(8.33)$ & 24 & \\
Volunteer & $0(0.00)$ & 2 & 0.32 \\
Levels of Certification & & & \\
First Responders & $0(0.00)$ & 9 & \\
EMT-Basics ${ }^{\text {a }}$ & $8(7.48)$ & 107 & \\
EMT-Intermediate ${ }^{\mathrm{a}}$ & $3(21.43)$ & 14 & \\
Paramedics & $22(27.50)$ & 80 & \\
Critical Care Paramedics & $12(32.43)$ & 37 & 0.0005 \\
Years of Experience & & & \\
$<5$ & $7(8.05)$ & 87 & \\
6-10 & $6(10.71)$ & 56 & \\
11-15 & $5(14.71)$ & 34 & \\
$>15$ & $27(38.57)$ & 70 & $<.0001$ \\
\hline${ }^{\mathrm{a} E M T=\text { Emergency Medical Technician }}$ & & \\
${ }^{*}$ P-value is calculated by Chi Square test & & \\
\hline
\end{tabular}

\begin{tabular}{llc}
\hline \multicolumn{2}{l}{ TABLE 3.7.3: Adjusted Logistic Regression Modeling of NSIs (n=247) } \\
\hline Characteristic (Reference) & $\begin{array}{l}\mathbf{O R}^{\mathbf{a}} \\
\left.\mathbf{( 9 5 \%}^{\mathbf{9}} \mathbf{C I}^{\mathbf{b}}\right)\end{array}$ & p-value \\
\hline $\begin{array}{l}\text { Gender (Male) } \\
\quad \text { Female }\end{array}$ & $1.64(0.71-3.75)$ & 0.23 \\
$\begin{array}{l}\text { Residence (Rural areas) } \\
\quad \text { Urban areas }\end{array}$ & $1.81(0.76-4.26)$ & 0.17 \\
Needlestick Training (Yes) & & 0.33 \\
$\quad$ No & $1.83(0.59-7.11)$ & \\
Age (18-29) & $1.25(0.35-4.49)$ & 0.72 \\
30-39 & $0.70(0.14-3.30)$ & 0.65 \\
40-49 & $2.35(0.44-12.10)$ & 0.31 \\
$50-59$ & $2.79(0.26-30.31)$ & 0.38 \\
$60+$ & &
\end{tabular}




\begin{tabular}{|c|c|c|}
\hline \multicolumn{3}{|c|}{ Employment status (Full-time) } \\
\hline Part-time/ Volunteer* & $0.41(0.05-1.77)$ & 0.28 \\
\hline \multicolumn{3}{|c|}{ Levels of Certification (Critical Care Paramedics) } \\
\hline Responder*/ EMT-Basic & $0.35(0.10-1.18)$ & 0.09 \\
\hline EMT-Intermediate & $0.95(0.15-4.78)$ & 0.95 \\
\hline Paramedics & $1.16(0.46-3.05)$ & 0.74 \\
\hline \multicolumn{3}{|l|}{ Years of Experience $(<5)$} \\
\hline $6-10$ & $0.82\left(0.21 \_3.05\right)$ & 0.77 \\
\hline $11-15$ & $0.92(0.18-4.72)$ & 0.92 \\
\hline$>15$ & $3.48(0.78-17.76)$ & 0.11 \\
\hline
\end{tabular}


FIGURE 3.7.1: Stratification of Gender and Residence to Evaluate the Relationship with NSIs $(n=247)$

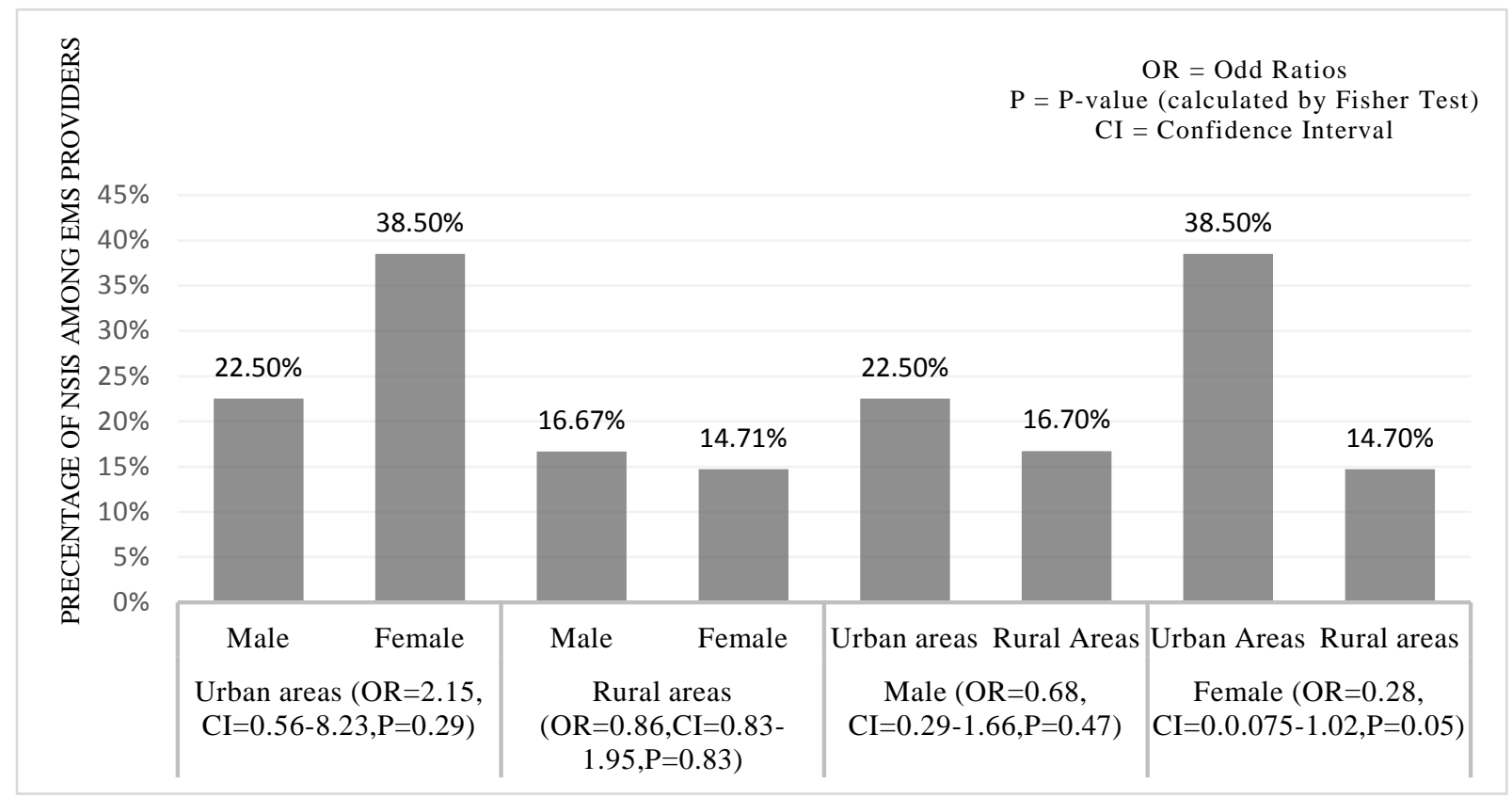

CHAPTER 4: Occupational Exposure to Blood and body fluids among Health Care Workers 1. INTRODUCTION 
The primary role of healthcare workers (HCWs) is to care for sick and injured patients. The definition of HCWs is any person whose role is directly associated with healthcare, including physicians, nurses, dentists, medical technicians, medical assistants, and students in the healthcare field [1]. Unsurprisingly, HCWs can confront some level of occupational exposure to various forms of hazards including sharps injuries, harmful exposures to chemicals and hazardous drugs, back injuries, latex allergy, violence, and stress [2]. HCWs can be exposed to blood or bodily fluids through mucous membranes, non-intact skin contact, or percutaneous injuries. Previous studies revealed a high level of occupational exposure to blood and bodily fluids among HCWs [3, 4, 5, and 6]. For example, in one study, an estimated $82.1 \%$ of HCWs experienced percutaneous injuries, and $48.7 \%$ experienced other types of routes of exposure to blood and bodily fluids throughout their work in the field [4]. There is evidence of high incidences of exposure to blood and bodily fluids among HCWs, with an estimated $44 \%$ of exposure via needlestick injuries, $31 \%$ of other routes of percutaneous injuries, and the rest due to non-percutaneous exposure [5]. A pervious study showed that occupational exposure to blood and bodily fluids through non-percutaneous and percutaneous injuries are more common among HCWs than the general population [7]. Due to the high risk of exposure to harmful pathogens, the goal of universal precautions was to diminish HCWs' risk of exposure to harmful pathogens across the globe [8]. Therefore, these high rates of occupational exposure to blood and bodily fluids can be prevented by the use of universal precautions. The extensive failure to comply with universal precautions guidelines significantly increases the rates of exposure, thus endangering HCWs and their patients [4]. An example of the lack of these prevention measures includes improper methods to prevent needlestick injuries, particularly in instances where more than half of HCWs did not use protective gloves and also did not wash their hands after having contact with patients [5]. Additionally, the study revealed that HCWs' education level about different types of infectious diseases and universal precautions compliance were not at an acceptable level [9]. The study estimates approximately more than twothirds of participants reported that they had not been trained on the prevention of blood-borne pathogens and the risks of occupational exposure [9]. Some types of occupations of HCWs may be more susceptible to exposure 
of bloodborne pathogens. A lack of information exists regarding different occupations of HCWs that are most likely to be exposed to blood and bodily fluids through percutaneous or non-percutaneous exposure. The objective of this study was to evaluate blood and bodily fluids exposure incidents among HWCs.

\section{METHODS}

\subsection{Study Design and Population.}

This project was a retrospective cohort study comprising data that was collected from J. W. Ruby Memorial Hospital between January 1, 2014 and August 15, 2017. J. W. Ruby Memorial Hospital is a private medical teaching facility and the largest facility in the West Virginia University medicine family [10]. It consists of a 645-bed academic medical center and was the only hospital included in this study. The hospital is located in the city of Morgantown, which is in the northern part of West Virginia. As of the 2016 census, the population was 30,855 [11]. The Employee Health Clinic in the hospital is open to all employees, covering annual tuberculosis skin testing, immunizations, laser eye exams, blood borne pathogen exposure, flu shots, and lipid panels. The dataset was received in form of an Excel document and was de-identified and anonymous.

\subsection{Study Sample}

All reports were recorded and uploaded electronically through the Employee Health Clinic in Ruby Memorial Hospital. Data included de-identified codes, occupations, types of exposure to blood borne pathogens, its routes of exposure, infectious diseases exposure, and time and date of incidents. For our analysis, occupations were categorized into major categories, including dental worker, health aide/attendant, laboratory technician, nurse, physician (surgical), technician (surgical) and technician/therapist. Non-healthcare workers were excluded from the analysis. Types of exposure to blood borne pathogens were categorized into percutaneous injuries and non-percutaneous exposure. Percutaneous injuries include any exposure through needlesticks, surgical sharp instruments, or glass, while non-percutaneous exposure includes any physical 
exposure to blood and bodily fluids like splashing or touching blood or body fluids. Routes of percutaneous injuries were analyzed, whether transmitted through needlestick, sharp instruments, or glass as well as how deep injuries were (superficial, moderate, or deep). Incident data were categorized by year $(2014,2015,2016,2017)$, and incident time was categorized into to three shifts: Shift 1 (8:01 AM-16:00 PM), Shift 2 (16:01 PM-0:00 AM), and Shift 3 (0:01AM-8:00AM). Infectious disease exposure was analyzed based on the type of disease, including the hepatitis B virus (HBV), hepatitis C virus (HCV), and human immunodeficiency virus (HIV).

\subsection{Data Analysis}

Data analysis was performed using Statistical Analysis System (SAS) software, Version 9.4. Descriptive statistics were performed first to summarize characteristics of HCWs regarding the types of exposure and routes of percutaneous injuries, including summary tables, frequencies, and proportions. Chi-square tests were used to compare categorical variables. All findings are reported using $95 \%$ confidence intervals (CIs). Differences at the $\alpha=0.05$ level were considered statistically significant.

\section{RESULTS}

926 incidents were received between January 1, 2014 and August 15, 2017, including 913 documented as blood or body fluid exposure incidents and 13 documented as other incidents. 263 of 926 were not documented with an occupation, and 662 occupations were documented as varying types of HCWs and nonHCWs. 487 incidents of 662 were documented as routes of percutaneous injuries, and 625 incidents were documented with exposure to infectious diseases. In the final analysis, exposure incidents were primary outcomes, and HCWs occupations were the primary independent variable while non-HCWs occupations (8 out of 662) were deleted from the analysis. 655 incident reports were documented and finalized in regards to blood or body fluid exposure (Table 1). 149 (22.74\%) incidents were non-percutaneous, and 506 (77.25\%) incidents were percutaneous. The majority of the HCWs $(331,50.53 \%)$ were nurses who were occupationally exposed, with 239 (47.23\%) incidents reporting percutaneous injuries and 92 (61.74\%) incidents reporting non- 
percutaneous exposure. The majority of exposure incidents occurred in $2016(224,34.20 \%)$ with $171(33.79 \%)$ incidents of percutaneous injuries and $53(35.57 \%)$ incidents of non-percutaneous injuries. In addition, the majority of exposure incidents occurred during morning shifts of 8:01 AM-16:00 PM (348, 53.13\%), with 140 (27.66\%) incidents of percutaneous injuries and 70 (46.97\%) incidents of non-percutaneous injuries. A chisquare test was used to evaluate the relationship between exposure incidents of HCWs and events. There was a statistically significant association only between occupations and exposure incidents $(\mathrm{p}$-value $[\mathrm{p}]=<.0001)$ (Table 1).

487 incident of percutaneous injuries reported the routes of exposure caused by needle hollow bore, surgical instruments, or other sharp items or glass (Table 2). The majority of incidents were caused by needle hollow bore $(278,75.08 \%)$, followed by surgical instruments or other sharp items $(199,40.86 \%)$, while only 10 $(2.05 \%)$ incidents were caused by glass. For needle hollow bore incidents, the majority of incidents were among nurses $(197,70.86 \%)$, were in 2016 (97, 34.89\%), occurred during morning shifts (8:01 AM-16:00 PM, 131, 47.12\%), and were superficial injuries $(234,84.17 \%)$. However, the majority of incidents caused by surgical instruments or other sharp items were among physicians (108, 54.27\%) and surgical technicians $(36,18.09 \%)$, were in $2016(66,33.17 \%)$, occurred during morning shifts (8:01 AM-16:00 PM, 132, 66.33\%), and were superficial injuries $(179,89.95 \%)$. The incidents caused by glass had the lowest rate of incidents among all variables. Chi-square tests were used to evaluate the relationship between the routes of incidents caused and characteristics of the incidents. There was a statistically significant association between occupations and the routes of incidents caused $(\mathrm{p}=<.0001)$, where needle stick injuries had the dramatically highest proportion (75.08\%) among other routes, specifically among nurses. In addition, there was a statistically significant association between shift time and the routes of incidents caused, where injuries most likely occurred during morning shifts. 
524 incidents involved exposure to infectious diseases such as HBV and HCVs (Table 3). 591 (94.65\%) incidents were exposed to HBV, and $5.44 \%$ were not exposed to HBV (Table 3). The exposure to HBV was relatively similar between non-percutaneous and percutaneous incidents, with $90.03 \%$ and $95.72 \%$, respectively. Chi-square tests were used to evaluate the relationship between the exposure incidents and the exposure to infectious diseases. There was a statistically significant association between HBV exposure and exposure incidents ( $\mathrm{p}=0.01) .517(82.72 \%)$ incidents were exposed to $\mathrm{HCV}$, and $17.28 \%$ were not exposed to HCV (Table 3). However, the exposure to HCV had a quite similar proportion between non-percutaneous and percutaneous incidents, with $23.13 \%$ and $15.68 \%$, respectively. Accordingly, there was a statistically significant association between HCV exposure and exposure incidents $(\mathrm{p}=0.04)$.

\section{DISCUSSION}

HCWs deal with different conditions of ills and therefore are occupationally exposed to a variety of infectious diseases. This study evaluated the occupational exposure incidents among HWCs. This study identified the circumstances of exposure to blood pathogens through percutaneous and non-percutaneous exposure among HCWs and possible approaches to prevent such incidents.

A majority of literature, conducted in developing countries, shows that occupational exposure to blood and bodily fluids is at an increased frequency among HCWs $[3,4,5,6,7]$. There is little research in developed counties regarding this specific issue. However, these findings support our study, where we found that 655 incidents regarding blood and bodily fluids exposure occurred with different occupations of HCWs in a hospital between January 1, 2014 and August 15, 2017 in Morgantown, West Virginia.

In this study, the majority of incidents $(n=506,77.25 \%)$ reported percutaneous injuries and $22.74 \%$ ( $n=149)$ reported non-percutaneous exposure to blood and bodily fluids (Table 1). Previous studies support our findings that percutaneous injuries lead to higher incidents than non-percutaneous exposure [12, 13, 14]. 
Occupation is another factor related to exposure incidents among HCWs; as various studies highlighted, exposure to blood borne pathogens predominantly occur among nurses, physicians, and lab workers [15, 16]. However, our study stressed nurses are the occupational category with the highest proportion exposed to blood and bodily fluids (50.53\%), followed by physicians (surgical, 25.64\%), compared to other occupations. Nurses make contact with patients for longer periods of time compared to other occupations, which consequently exposes them to a variety of types of exposure, including needlestick and non-intact skin exposure or other ways of exposure. Registered Nurses (RNs) have a high rate of needle stick injuries, and in fact an estimated $70.4 \%$ of RNs experienced at least one needlestick injury in one year, and less experienced RNs experienced more needlestick injuries compared to RNs with more experience [17]. Published studies reveal most nurses inadequately comply with universal precautions worldwide, where nurses are selective regarding the implementation of universal precautions recommendations, which is strong evidence of the low level of compliance of universal precautions $[18,19]$. In our study, we included all different types of nurses in one category. Future studies should assess the type and duties of nurses in order to estimate the magnitude of the exposure and therefore find solutions to minimize exposure.

The majority of percutaneous injuries incidents were caused by needle hollow bore $(75.08 \%)$, followed by surgical or other sharp items (40.86\%). Previous studies are consistent with our study, as needlestick injuries are the most frequent items resulting in exposure to blood and bodily fluids [20,21]. Occupations were associated with the occurrence of percutaneous injuries, which is consistent with past studies $[15,16]$. Specifically, percutaneous injuries caused by needle hollow bore were the most frequent incidents among nurses with $70.86 \%$, whereas surgical instruments or other sharp items were the most frequent incidents among physicians (surgical) with 54.27\%. In addition, shift times when injuries occurred were positively associated with percutaneous injuries, where morning shifts comprised a greater percentage of injures among HCWs. There was a previous study showing the majority of exposures occurred during the morning shift [22]. This may be attributed to busy schedules and greater demands of patients during morning shifts. However, there are 
previous studies inconsistent with our results, as fatigue and sleep deprivation affect extended shifts more than regular working hours, so the night shift causes high percentages of percutaneous injuries among HCWs [23, 24]. Future research should examine differences between the characteristics of HCWs regarding types of shifts resulting in percutaneous injuries.

HCWs encounter all type of ills during performance their duties, resulting in concerns regarding transmission of blood borne pathogens. Cases of acute hepatitis B increased $20.7 \%$ to 3,370 cases in 2015, and cases of acute HCV infection increased more than 2.9-fold from 2010 through 2015 [25]. In our study, we found that exposure to hepatitis $\mathrm{B}$ and $\mathrm{C}$ was associated with reporting exposure incidents among HCWs. Those more exposed to hepatitis $\mathrm{B}$ and $\mathrm{C}$ had more reporting of exposure incidents. HCWs are most likely to report exposure incidents when the patient has an infectious disease. Otherwise, when patients are free of infectious diseases, they might not report any exposure incidents. Previous studies support our views; underreporting of blood and body fluid exposures among HWCs is common because they think that such exposures are not critical $[26,27]$. Accordingly, future research should investigate whether or not underreporting of blood and body fluid exposure incidents is common.

This study has some limitations. Underreporting of blood and bodily fluids exposure is missed in our data, resulting in an underestimate of the true magnitude of the problem. For example, some HCWs who were exposed tended to report, and others did not report the incidents because they might believe the exposure was not significant. Therefore, these results cannot necessarily be generalized, as the results underestimate the problem. Moreover, the dataset lacks information, including gender, years of experience, shift schedule, and blood pathogen training attendance. This information can help to assess different characteristics of HCWs and also estimate the true burden of the workload of HCWs. 


\section{CONCLUSION}

Exposure to blood and body fluid is a concern among HCWs. The majority of incidents reported percutaneous injuries. Exposure to blood borne pathogens largely occur among nurses and physicians. Future studies should assess all types and duties of nurses and physicians in order to estimate the magnitude of the exposure to therefore solve these problems. The majority of percutaneous injuries incidents were caused by needle hollow bore, followed by other sharp items. Additionally, morning shifts comprised a greater percentage of percutaneous injuries among HCWs. Future research should examine differences based on characteristics of HCWs regarding types of shifts resulting in percutaneous injuries. Those more exposed to hepatitis B and C had more reporting of exposure incidents. Future research should investigate whether underreporting of blood and body fluid exposures incidents is common among those with patients who are free of infectious diseases. 


\section{REFERENCES}

1. Kuhar, D. T., Henderson, D. K., Struble, K. A., Heneine, W., Thomas, V., \& Cheever, L. W. (2013). Updated US public health service guidelines for the management of occupational exposures to human immunodeficiency virus and recommendations for postexposure prophylaxis. Infection Control and Hospital Epidemiology, 34(9), 875-892.

2. Centers for Disease Control and Prevention (CDC). (2017). HEALTHCARE WORKERS. The National Institute for Occupational Safety and Health (NIOSH). Last updated: March 14, 2017. Retrieved on October 7, 2017, from https://www.cdc.gov/niosh/topics/healthcare/default.html

3. Zhang, M., et al. (2009) Occupational exposure to blood and body fluids among health care workers in a general hospital, China. American Journal of Industrial Medicine, 52(2), 89-98.

4. Liu, X., Sun, X., van Genugten, L., Shi, Y., Wang, Y., Niu, W., \& Richardus, J. H. (2014). Occupational exposure to blood and compliance with standard precautions among health care workers in Beijing, China. American Journal of Infection Control, 42(3), e37.

5. Sabermoghaddam, M., Sarbaz, M., Lashkardoost, H., Kaviani, A., Eslami, S., \& Rezazadeh, J. (2015). Incidence of occupational exposure to blood and body fluids and measures taken by health care workers before and after exposure in regional hospitals of a developing country: A multicenter study. American Journal of Infection Control, 43(10), 1137.

6. Hajjaji, D. M., Chaabouni, T., Jmal, H. K., Messadi, A. F., Abdennadher, M., Hammami, A., \& Masmoudi, M. L. (2014). Occupational blood exposure among health care personnel and hospital trainees. The International Journal of Occupational and Environmental Medicine, 5(1), 57-61.

7. Coppola, N., De Pascalis, S., Onorato, L., Calò, F., Sagnelli, C., \& Sagnelli, E. (2016). Hepatitis B virus and hepatitis $\mathrm{C}$ virus infection in healthcare workers. World Journal of Hepatology, 8(5), 273.

8. Hamlyn, E., \& Easterbrook, P. (2007). Occupational exposure to HIV and the use of post-exposure prophylaxis. Occupational Medicine, 57(5), 329-336.

9. Hosoglu, S., Akalin, S., Sunbul, M., Otkun, M., \& Ozturk, R. (2011). Healthcare workers' compliance with universal precautions in turkey. Medical Hypotheses, 77(6), 1079-1082. doi:10.1016/j.mehy.2011.09.007.

10. WVU Medicine. (2017). J. W. Ruby Memorial Hospital WVU Physicians. Retrieved October 2, 2017, from http://wvumedicine.org/ruby-memorial-hospital/about-us/

11. United States Census Bureau. (2016). Quick Facts, Morgantown City, West Virginia. Retrieved October 7, 2017, from https://www.census.gov/quickfacts/fact/table/morgantowncitywestvirginia/PST045216

12. Deuffic-Burban, S., Delarocque-Astagneau, E., Abiteboul, D., Bouvet, E., \& Yazdanpanah, Y. (2011). Blood-borne viruses in health care workers: prevention and management. Journal of Clinical Virology, 52(1), 4-10.

13. Gönen, I., \& Geyik, M. F. (2011). Percutaneous injuries among healthcare workers at a general hospital. Journal of Microbiology and Infectious Diseases, 1(1).

14. Mbaisi, E. M., Wanzala, P., \& Omolo, J., 2013. Prevalence and factors associated with percutaneous injuries and splash exposures among health-care workers in a provincial hospital, Kenya, 2010. Pan African Medical Journal, 14(1). 
15. Pérez-Diaz, C., Calixto, O. J., Faccini-Martínez, Á. A., Bravo-Ojeda, J. S., Botero-García, C. A., UribePardo, E., ... \& Osorio, J. (2015). Occupational exposure to blood borne pathogens among healthcare workers: A cross-sectional study of a registry in Colombia. Journal of Occupational Medicine and Toxicology, 10(1), 45.

16. Helena Palucci Marziale, M., Ludmilla Rossi Rocha, F., Lúcia do Carmo Cruz Robazzi, M., Maria Cenzi, C., Ehmke Cardoso dos Santos, H., \& Elisa Mendes Trovó, M. (2013). Organizational influence on the occurrence of work accidents involving exposure to biological material. Rev Lat Am Enfermagem, 21, 199-206.

17. Cho, E., Lee, H., Choi, M., Park, S. H., Yoo, I. Y., \& Aiken, L. H. (2013). Factors associated with needlestick and sharp injuries among hospital nurses: A cross-sectional questionnaire survey. International Journal of Nursing Studies, 50(8), 1025-1032. doi:10.1016/j.ijnurstu.2012.07.009

18. Efstathiou, G., Papastavrou, E., Raftopoulos, V., \& Merkouris, A. (2011). Compliance of cypriot nurses with standard precautions to avoid exposure to pathogens. Nursing \& Health Sciences, 13(1), 53-59. doi:10.1111/j.1442-2018.2011.00576.x

19. Pereira, F. M. V., Lam, S. C., Chan, J. H. M., Malaguti-Toffano, S. E., \& Gir, E. (2015). Difference in compliance with standard precautions by nursing staff in Brazil versus Hong Kong. American Journal of Infection Control, 43(7), 769.

20. Martins, A., Coelho, A. C., Vieira, M., Matos, M., \& Pinto, M. L. (2012). Age and years in practice as factors associated with needlestick and sharps injuries among health care workers in a Portuguese hospital. Accident Analysis \& Prevention, 47, 11-15.

21. Kakizaki, M., Ikeda, N., Ali, M., Enkhtuya, B., Tsolmon, M., Shibuya, K., \& Kuroiwa, C. (2011). Needlestick and sharps injuries among health care workers at public tertiary hospitals in an urban community in Mongolia. BMC Research Notes, 4(1), 184.

22. Chalya, P. L., Seni, J., Mushi, M. F., Mirambo, M. M., Jaka, H., Rambau, P. F., ... \& Kalluvya, S. E. (2015). Needle-stick injuries and splash exposures among health-care workers at a tertiary care hospital in north-western Tanzania. Tanzania Journal of Health Research, 17(2).

23. Wicker, S., Ludwig, A. M., Gottschalk, R., \& Rabenau, H. F. (2008). Needlestick injuries among health care workers: Occupational hazard or avoidable hazard?. Wiener Klinische Wochenschrift, 120(15), 486492.

24. Dembe, A. E., Delbos, R., \& Erickson, J. B. (2009). Estimates of injury risks for healthcare personnel working night shifts and long hours. Quality and Safety in Health Care, 18(5), 336-340.

25. Centers for Disease Control and Prevention (CDC). (2015). Surveillance for Viral Hepatitis - United States, 2015. Last updated: June 19, 2017. Retrieved on October 7, 2017, from https://www.cdc.gov/hepatitis/statistics/2015surveillance/commentary.htm

26. Voide, C., Darling, K. E., Kenfak-Foguena, A., Erard, V., Cavassini, M., \& Lazor-Blanchet, C. (2012). Underreporting of needlestick and sharps injuries among healthcare workers in a Swiss University Hospital. Swiss Med Wkly, 142(0).

27. Kessler, C. S., McGuinn, M., Spec, A., Christensen, J., Baragi, R., \& Hershow, R. C. (2011). Underreporting of blood and body fluid exposures among health care students and trainees in the acute care setting: A 2007 survey. American Journal of Infection Control, 39(2), 129-134. 


\section{Tables and Figures}

TABLE 4.7.1: Demographics and Relationships of Healthcare Workers Reporting Occupational Exposure $(n=655)$

\begin{tabular}{|c|c|c|c|c|}
\hline & \multicolumn{4}{|c|}{ Exposure Incidents } \\
\hline & $\begin{array}{l}\text { Non- } \\
\text { Percutaneous } \\
(\%)\end{array}$ & $\begin{array}{l}\text { Percutaneous } \\
\text { Injuries (\%) }\end{array}$ & $\mathrm{n}^{\mathrm{a}}(\%)$ & p-value* \\
\hline \multicolumn{5}{|l|}{ Occupation } \\
\hline Dental worker & $0(0.00)$ & $10(1.98)$ & $10(1.52)$ & \\
\hline Health aide/attendant & $9(6.04)$ & $22(4.35)$ & $31(4.73)$ & \\
\hline Laboratory technician & $4(2.68)$ & $24(4.74)$ & $28(4.27)$ & \\
\hline Nurse & $92(61.74)$ & $239(47.23)$ & $331(50.53)$ & \\
\hline Other healthcare occupations & $4(2.68)$ & $5(0.99)$ & $9(1.37)$ & \\
\hline Physician, surgical & 21(14.09) & $147(29.05)$ & $168(25.64)$ & \\
\hline Technician, surgical & $4(2.68)$ & $46(9.09)$ & $50(7.63)$ & \\
\hline Technician/therapist, other & $15(10.07)$ & $13(2.57)$ & $28(4.27)$ & $<.0001$ \\
\hline \multicolumn{5}{|l|}{ Year exposure occurred } \\
\hline 2014 & $24(16.11)$ & $55(10.87)$ & $79(12.06)$ & \\
\hline 2015 & $39(26.17)$ & $142(28.06)$ & $181(27.63)$ & \\
\hline 2016 & $53(35.57)$ & $171(33.79)$ & $224(34.20)$ & \\
\hline 2017 (mid-Aug) & $33(22.15)$ & $138(27.27)$ & $171(26.10)$ & 0.25 \\
\hline \multicolumn{5}{|l|}{ Shift exposure occurred (time) } \\
\hline Shift $1(8: 01-16: 00)$ & $70(46.97)$ & $278(54.94)$ & $348(53.13)$ & \\
\hline Shift $2(16: 01-0.00)$ & $45(30.20)$ & $140(27.66)$ & $185(28.24)$ & \\
\hline \multirow[t]{2}{*}{ Shift $3(0.01-8: 00)$} & $34(20.13)$ & $88(17.39)$ & $122(18.62)$ & 0.17 \\
\hline & $149(22.74)$ & $506(77.25)$ & 655 & \\
\hline
\end{tabular}

${ }^{a} n=271$ of 926 reported were deleted due to missing values of occupations and as well as the exclusion of non-HCWs. 
TABLE 4.7.2: Demographics and

Relationships of Healthcare Workers Reporting

Routes of Percutaneous Injuries $(n=487)$

\begin{tabular}{|c|c|c|c|c|c|}
\hline & \multicolumn{5}{|c|}{ Routes of Incident Caused } \\
\hline & $\begin{array}{l}\text { NEEDLE- } \\
\text { HOLLOW- } \\
\text { BORE (\%) }\end{array}$ & $\begin{array}{l}\text { SURGICAL } \\
\text { INSTRUMENT } \\
\text { OR OTHER } \\
\text { SHARP ITEM }(\%)\end{array}$ & $\begin{array}{l}\text { GLASS } \\
(\%)^{*}\end{array}$ & $\mathbf{n}^{\mathbf{a}}$ & $\begin{array}{l}\text { P- } \\
\text { value }\end{array}$ \\
\hline \multicolumn{6}{|l|}{ Occupation } \\
\hline Dental worker & $3(1.08)$ & $7(3.25)$ & $0(0.00)$ & 10 & \\
\hline Health aide/attendant & 11(3.96) & $8(4.02)$ & $0(0.00)$ & 19 & \\
\hline Laboratory technician & $23(8.27)$ & $0(0.00)$ & $0(0.00)$ & 23 & \\
\hline Nurse & 197(70.86) & $33(16.58)$ & $4(40.0)$ & 234 & \\
\hline Other healthcare occupations & $2(0.72)$ & $3(1.51)$ & $0(0.00)$ & 5 & \\
\hline Physician, surgical & $30(10.79)$ & $108(54.27)$ & $1(10.0)$ & 139 & \\
\hline Technician, surgical & $8(2.88)$ & $36(18.09)$ & $2(20.0)$ & 49 & \\
\hline Technician/therapist, other & $4(1.44)$ & $4(2.01)$ & $3(30.0)$ & 11 & $<.0001$ \\
\hline \multicolumn{6}{|l|}{ Year exposure occurred } \\
\hline 2014 & $32(11.51)$ & $20(10.05)$ & $1(10.0)$ & 53 & \\
\hline 2015 & $83(29.86))$ & $47(23.62)$ & $4(40.0)$ & 134 & \\
\hline 2016 & $97(34.89)$ & $66(33.17)$ & $4(40.0)$ & 167 & \\
\hline 2017 (mid-Aug) & $66(23.74)$ & $66(33.17)$ & $1(10.0)$ & 133 & 0.27 \\
\hline \multicolumn{6}{|l|}{ Shift exposure occurred } \\
\hline Shift $1(8: 01-16: 00)$ & $131(47.12)$ & $132(66.33)$ & $4(40.00)$ & 267 & \\
\hline Shift 2 (16:01-0.00) & $84(30.22)$ & $49(24.62)$ & $1(10.00)$ & 134 & \\
\hline Shift 3 (0.01-8:00) & $63(22.66)$ & $18(9.05)$ & $5(50.00)$ & 86 & $<.0001$ \\
\hline \multicolumn{6}{|l|}{ INJURY_DEPTH } \\
\hline Superficial & $234(84.17)$ & $179(89.95)$ & $9(90.0)$ & 422 & \\
\hline \multirow[t]{2}{*}{ Moderate $^{\mathrm{b}}$} & $44(15.63)$ & $20(10.05)$ & $1(10.0)$ & 65 & 0.17 \\
\hline & $278(75.08)$ & $199(40.86)$ & $10(2.05)$ & 487 & \\
\hline \multicolumn{6}{|c|}{$\begin{array}{l}\text { a. Only } 487 \text { HCWs reported the routes of } \\
\text { precautions injuries, so } 168 \text { are } \\
\text { missing. } \\
\text { b. No one reported deep injuries, so it was } \\
\text { excluded from analysis }\end{array}$} \\
\hline
\end{tabular}


TABLE 4.7. 3: Healthcare Workers Reporting Occupational Exposure to Infectious Diseases ( $n=625)$

\begin{tabular}{|c|c|c|c|c|}
\hline Exposure* & $\begin{array}{l}\text { Non- } \\
\text { Percutaneous } \\
(\%) \\
\end{array}$ & $\begin{array}{l}\text { Percutaneous } \\
(\%)\end{array}$ & $\mathrm{n}(\%)$ & $\begin{array}{l}\text { p- } \\
\text { value }\end{array}$ \\
\hline \multicolumn{5}{|c|}{ Hepatitis B Exposure } \\
\hline Yes & $121(90.03)$ & $470(95.72)$ & $591(94.65)$ & \multirow[b]{2}{*}{0.01} \\
\hline No & $13(9.30)$ & $21(4.25)$ & $34(5.44)$ & \\
\hline \multicolumn{5}{|c|}{ Hepatitis C Exposure } \\
\hline Yes & $31(23.13)$ & $77(15.68)$ & $108(17.28)$ & \multirow[b]{2}{*}{0.04} \\
\hline \multirow[t]{2}{*}{ No } & $103(78.87)$ & $414(84.32)$ & $517(82.72)$ & \\
\hline & 134 & 491 & 625 & \\
\hline
\end{tabular}

*HIV test indication was not included due to low sample size (36) and was therefore deleted from analysis. 
